\title{
3D technologies for intangible cultural heritage preservation-literature review for selected databases
}

\author{
Maria Skublewska-Paszkowska*+®i], Marek Milosz, Pawel Powroznik ${ }^{\dagger}$ and Edyta Lukasik
}

\begin{abstract}
Conservation of cultural heritage is nowadays a very important aspect of our lives. Thanks to such legacy we gain knowledge about our ancestors, methods of production and ways of their life. The rapid development of 3D technology allows for more and more faithful reflection of this area of life. The rich cultural heritage, both tangible and intangible, can be preserved for future generations due to the use of advanced $3 \mathrm{~d}$ technologies. They provide the means of documenting, recovering and presenting items of cultural heritage. Not only buildings or monuments are taken into account. An important aspect of our culture is intangible cultural heritage $(\mathrm{ICH})$, including acting, crafting or storytelling, passed down from generation to generation. Due to the rapid development of civilisation and the migration of people, this type of culture is often forgotten. That is why the preservation of $\mathrm{ICH}$ is an important element of today world. The main aim of this study, on the basis of the gathered papers, is to identify: (1) the general state of use of 3D digital technologies in $\mathrm{ICH}$; (2) the topics and themes discussed; (3) the technologies used in the study; (4) locations of research centres conducting such studies; and (5) the types of research carried out. The methodology consists of the following main steps: defining study questions, searching query development, selection of publications in Scopus, Web of Knowledge and IEEE Xplore, finally the study execution and the analysis of the obtained results. The results show that for ICH the most often used technologies are: 3D visualisation, 3D modelling, Augmented Reality, Virtual Reality and motion capture systems.
\end{abstract}

Keywords: Intangible cultural heritage, 3D technologies, Literature analysis

\section{Introduction}

The definition of cultural heritage $(\mathrm{CH})$ has been changing together with the world developments in conservation $[1,2]$. According to the United Nations Educational, Scientific and Cultural Organisation (UNESCO), heritage has a very wide definition that includes both tangible cultural heritage $(\mathrm{TCH})$ and intangible cultural heritage (ICH) [2]. The former focuses on monuments, collections of objects, archaeological findings and others [3-10]. UNESCO's 2003 Convention for the Safeguarding of ICH defined five areas that belong to it [11]:

\footnotetext{
${ }^{*}$ Correspondence: maria.paszkowska@pollub.pl

${ }^{\dagger}$ Maria Skublewska-Paszkowska and Pawel Powroznik contributed equally

to this work

Department of Computer Science, Lublin University of Technology,

Nadbystrzycka 38D, Lublin, Poland
}

- oral traditions and expressions (e. g. language, storytelling);

- performing arts (e.g. singing, dancing, theatre, feasting);

- social practices, rituals and festive events;

- knowledge and practices concerning nature and the universe;

- knowledge and skills used to produce traditional crafts.

It must be stated that this definition of $\mathrm{ICH}$ is not a final one. There are different variations used locally in some countries, such as traditional plays and games, culinary traditions, animal husbandry, pilgrimage and places of memory.

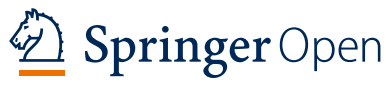

(c) The Author(s) 2021. Open Access This article is licensed under a Creative Commons Attribution 4.0 International License, which permits use, sharing, adaptation, distribution and reproduction in any medium or format, as long as you give appropriate credit to the original author(s) and the source, provide a link to the Creative Commons licence, and indicate if changes were made. The images or other third party material in this article are included in the article's Creative Commons licence, unless indicated otherwise in a credit line to the material. If material is not included in the article's Creative Commons licence and your intended use is not permitted by statutory regulation or exceeds the permitted use, you will need to obtain permission directly from the copyright holder. To view a copy of this licence, visit http://creativecommons.org/licenses/by/4.0/. The Creative Commons Public Domain Dedication waiver (http://creativeco mmons.org/publicdomain/zero/1.0/) applies to the data made available in this article, unless otherwise stated in a credit line to the data. 
The deliberate act of keeping cultural heritage from the present for the future is known as preservation, and is currently used in historical museums, cultural centres, scientific research, education and others [12]. One of the possibility to develop this process is application various $3 \mathrm{D}$ technologies. They allow to access to the culture heritage elements that are difficult to reach in a real world [10]. Preservation concerns the following fields of study: documentation, protection, reconstruction, restoration, conservation, dissemination and spreading. Documentation is connected with storing various types of information. Protection is defined as actions against damage, destruction or other loss of $\mathrm{CH}$. Reconstruction is a process of visualisation of $\mathrm{CH}$ objects for their better understanding. Restoration is a set of actions including the following tasks: integration and replacement of non-original elements, reconstruction, retouching and infilling. Conservation is about extending the life of cultural heritage while strengthening the transmission of its significant heritage messages and values [13]. Dissemination concerns representation and visualisation of $\mathrm{TCH}$ and $\mathrm{ICH}$ objects using modern technology [14]. Spreading is for accessing a possibly widest group of recipients in order to get them acquainted with cultural heritage.

Usually, tangible culture tends to last much longer than intangible culture. As a result of archaeological discoveries, some or all of the material things used in the past are preserved. A much more difficult situation concerns the intangible aspects of cultural life, which are passed down from generation to generation. The analysed materials show that human migration is one of the causes the forgetting and modification of this kind of culture [15-17]. Stories and experience are often forgotten or inaccurately communicated. Civilisation changes also result in the loss of indigenous culture. That is why the archiving of non-material culture for future generations is currently such an important initiative. ICH can be stored using a variety of analogue data, text, and two-dimensional (2D) technologies. Sometimes, however, it is not enough. In addition, over time analogue technologies are exposed to a natural loss of the quality of documented ICH. Digital technologies support ICH documentation processes and provide safer, more unchangeable capture and collection of ICH data. Moreover, a combination of various 3D technologies results in a better understanding of the topic and brings a new insights into the study [18].

There is a noticeable increase in the importance of 3D technology in science in various fields. The aim of the work was to perform a literature review on applied 3D digital technologies in the processing, presenting and protection of data related to intangible cultural heritage. The study was conducted on the basis of the three most popular databases (Scopus, Web of Knowledge and IEEE Xplore). The authors wanted to find out the answers whether these technologies are used in $\mathrm{ICH}$ area, what are the most popular topics, which countries are at the fore in such studies, and what types of research are being carried out. To the authors' knowledge, there is no such comparison regarding quantitative studies, geographic, technological and product cross-section.

3D digital technologies are used in studies concerning $\mathrm{CH}$ aspects, including 3D scanning, 3D modelling, Virtual Reality (VR) and Augmented Reality (AR) are often used to perform virtual presentations of monuments and ancient artefacts. 3D, 4D, motion capture systems allow for recording the way of performing activities, their consolidation and presentation for subsequent generations. Often digital technologies, e.g. audiovisual ones are combined with 3D techniques for better presentation of the elements of the culture. It is possible to register national dances (their successive sequences), perform traditional craft, pass the storytelling, ancient events or the knowledge about building in the ancient times. Despite their immateriality, these technologies make it possible to preserve this type of culture.

\section{Study motivation}

This study originated in 2015, arising from cooperation with many science and culture institutions from Europe and Central Asia in the area of digitalisation of cultural heritage. During scientific expeditions, researchers observed a relationship between $\mathrm{TCH}$ and $\mathrm{ICH}$ e.g. scanning objects and the method of their creation. Contacts related to the digitalisation of $\mathrm{TCH}$ resulted in the expansion of the author's interest in $\mathrm{ICH}$. One of the first steps towards expanding scientific interest is the analysis of the state of science and practice in the area of applying digital 3D technologies in $\mathrm{ICH}$.

State of the art was aimed to identify:

- the general state of use of 3D digital technologies in $\mathrm{ICH}$,

- topics and themes presented in the studies on the use of 3D digital technologies in $\mathrm{ICH}$,

- technologies used in the studies on the use of 3D digital technologies in $\mathrm{ICH}$,

- locations of research centres around the world that conduct studies using 3D digital technologies in $\mathrm{ICH}$,

- types of studies results in the 3D digital technologies in ICH area. 


\section{Methodology}

The methodology designed and used in this study is presented in Fig. 1.

The methodology of a literature review of 3D Digital Technologies in Intangible Cultural Heritage consists of the following stages (the names of the processes come from Fig. 1):

1. Study questions (Qs) development. Based on the study objectives defined in section Study motivation, study questions are formulated, the answers to which will be sought during a literature review. They define the scope of the collected data and the analysis of the results.
2. Search query development-defining a query to bibliographic databases in order to search for publications containing the results of theoretical and applied studies in the area of 3D Digital Technologies in Intangible Cultural Heritage.

3. Bibliographic databases (BDBs) source selection. Selection of databases from available BDBS that will be used in a review.

4. Implementation of the search and selection of publications. This operation involves typical steps: publication search, deduplication of search results, and applying inclusion and exclusion criteria.

5. Study execution. This stage includes the analysis of the content of the publications selected in the previ-

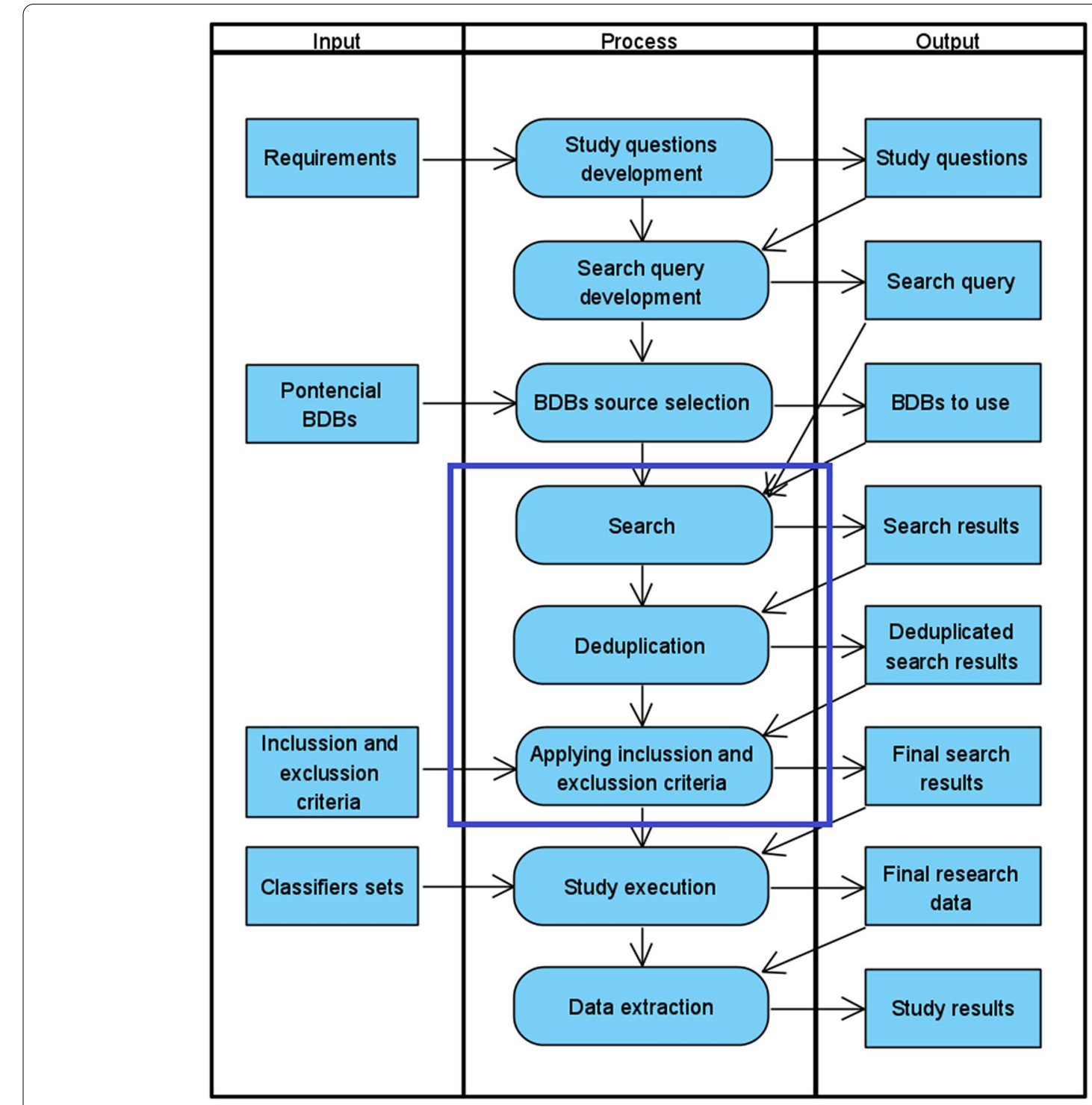

Fig. 1 Study methodolody 
ous stage. The analysis is carried out with the use of different sets of classifiers corresponding to the content of the Qs. The result is a database of publications assigned to different classifiers.

6. Data extraction - the analysis of the database created in stage 5.

\section{Study questions}

Due to the lack of similar studies in the area of 3D Digital Technologies in Intangible Cultural Heritage, on the basis of the aims defined in chapter Study motivation, the following questions can be formulated:

Q1. Is the use of 3D digital technologies in $\mathrm{ICH}$ developing now?

Q2. What are the most important topics and themes presented in the studies on the use of $3 \mathrm{D}$ digital technologies in $\mathrm{ICH}$ ?

Q3. What technologies are used in studies on the 3D digital technologies in $\mathrm{ICH}$ area?

Q4. What types of results in the $3 \mathrm{D}$ digital technologies in $\mathrm{ICH}$ area are presented?

\section{Search query}

The query defined by the words based on Table 1 was as follows: TITLE-ABS-KEY: (cultural OR folk) AND (intangible $O R$ elusive $O R$ non-material) AND (heritage $O R$ legacy OR inheritance) AND ( $3 D$ OR three-dimensional $O R$ "three dimensional") AND (history OR past) and it was too detailed and returned only 16 studies. That is why "history" and "past" were excluded. The query (cultural OR folk) AND ("intangible heritage" OR "elusive heritage" OR "non-material heritage") AND (3D OR three-dimensional OR "three dimensional") returned also too low number of results. So the final query was defined as follows: cultural AND (intangible OR non-material) AND heritage AND (3D OR three-dimensional OR "three dimensional").

This query was adapted to the formats used in the selected bibliographic databases.

\section{Source bibliographic databases}

The authors had access to the following bibliographic databases:

- InfonaNet;

- AccessEngineering;

- AIP / APS;

- EBSCOhost;

- EBSCO eBook;

- Emerald;

- IBUK Libra;

- EMIS Intelligence;

- IEEE Xplore;

- JCR;

- JSTOR;

- Medline;

- McGraw Hill eBook Library;

- Nature;

- MathSciNET;

- Science;

- Scopus;

- ScienceDirect;

- SpringerLink;

- Total Materia;

- Trans Tech Publications;

- Web of Knowledge;

- Wiley Online Library.

Three databases, the most prestigious in the field of technology, were selected for this purpose: Scopus, Web of Knowledge and IEEE Xplorer. These databases best fit the nature of the study in our area.

\section{Classifiers of scientific works used in the study}

In stage 5 of our search (Fig. 1), the content of scientific publications selected in stage 4 (Fig. 1) was analysed in detail. Each of them was classified, i.e. the appropriate features were assigned from the sets of classifiers. The sets of classifiers were developed so that from the created database it was possible to answer the study questions through Data extraction (Fig. 1).

Table 1 Analysed words in the following databases

\begin{tabular}{lc}
\hline Words & Reasons \\
\hline Cultural, folk & Formal synonym of culture \\
Heritage, legacy, inheritance & Formal synonym of heritage \\
Intangible, elusive, non-material & Formal synonym of intangible \\
3D, three-dimensional, three dimensional & Various methods of indicating 3D technology \\
History, past & General term to describe previous times \\
\hline
\end{tabular}


The following sets of publication content classifiers were used (* marked as extensible sets as the analysis of the content of the papers was initially defined, for which only the first few features were defined):

Set 1. Cultural Heritage types: $\mathrm{ICH}$ and $\mathrm{TCH} \& \mathrm{ICH}$. Set 2*. Keywords: Cultural Heritage, Intangible, 3D Modelling, Virtual Reality, Digitalisation.

Set 3. Publication types: Conference Paper, Article, Book, Conference Review, Editorial, Letter.

Set 4. Focus areas: Documentation, Protection, Reconstruction, Conservation, Dissemination, Spreading.

Set $5^{*}$. Study fields: initial was empty.

Set $6^{*}$. 3D technologies: 3D Modelling, Motion Capture, Virtual Reality, Augmented Reality, 3D Scanning, Photogrammetry.

Set 7*. Aims of studies: Promoting Heritage, Recognition, Visual Reconstruction, Education.

Set 8. Study results: Presentation, Virtual Exposition, Data Set, Web Application, AR Application, Museum, Mobile Application, Game.

\section{Detailed Literature Study}

\section{D technologies in $\mathrm{ICH}$}

The development of 3D technology has made it possible to preserve $\mathrm{ICH}$ in various fields. A great number of studies concerns craft, dance, storytelling, game-based education and various types of application for educational and documentary purposes. It is stated that sport and settlement are also a widely described issues.

\section{Craftsmanship studies}

Craftsmanship studies concern various types of traditional know-how of movements, human activities and manufacturing process. They involve tuna fishing [19], manufacturing authentic fabric in Transylvanian villages [20], Dongyang bamboo [21], traditional joinery technique [22], visualisation of the craftsman at work [23-25] - an example is presented in Fig. 2, artistic handicrafts in Lucchesia (Tuscany, Italy) [26], porcelain making crafts of Jingdezhen [27], traditional Chinese Gold Lacquer Wood Carving [28], sword motions-Japanese kenjutsu [29], traditional Tujia brocade skill [30] and the art of Franco Purini and Francesco Cellini [31]. Technologies used in the individual articles are presented in Table 2.

Digital technologies allow to document, store and protect traditional crafting. 3D recording enables capturing movements. For this purpose various acquisition systems are used, such as Kinect or Leap motion. Collected data is presented in the form of $3 \mathrm{D}$ models, which are later visualised in many environments.

\section{Art studies}

The subject of dance is widely discussed in articles on non-material culture. Its exemplary processing using motion capture tools is shown in Fig. 3.

Motion capture (both optical and based on accelerometers) and photogrammetry technology are often used for movement acquisition for various aspects of cultural, technical, academic, choreographic, spatial, commercial and educational purposes. The studies include traditional folk dances in Greece [32-42], Korea [43], China [44, 51],

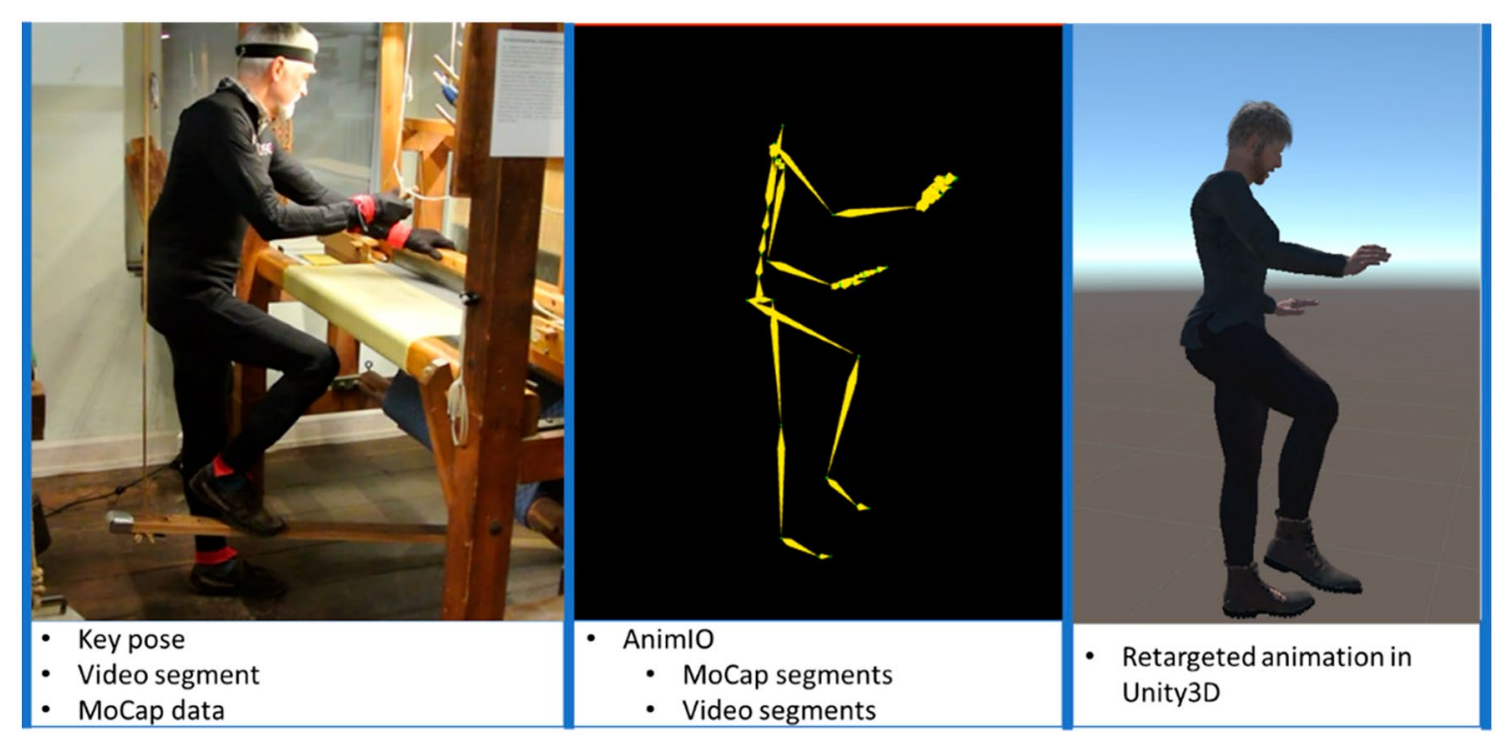

Fig. 2 Steps taken to create a virtual representation of the craftsman at work [23] 
Table 2 Technologies used in craftsmanship studies

\begin{tabular}{ll}
\hline Papers & Technologies used \\
\hline Repola et al. [19] & GIS-BIM System, 3D visualisation, 3D modelling \\
Cristin et al. [20] & 3D visualisation, AR, 3D modelling \\
Wu et al. [21] & VR, AR, CAD, Unity 3D, motion capture \\
Rossau et al. [22] & VR, 3D modelling \\
Partarakis et al. [23] & Motion capture, VR, 3D modelling \\
Jeong et al. [24] & Motion capture, 3D modelling, AR \\
Koutsabasis et al. [25] & Motion capture, 3D visualisation, 3D modelling \\
Carrozzino et al. [26] & VR, 3D visualisation, 3D modelling \\
Wang et al. [27] & 3D modelling, VR \\
Lou et al. [28] & 3D printing \\
Aoki et al. [29] & Motion capture, VR \\
Zhao et al. [30] & Motion capture, 3D visualisation, 3D modelling \\
Farroni et al. [31] & 3D visualisation, 3D modelling \\
\hline
\end{tabular}

Portugal [45], South Asia [46], Thailand [47-50], Slovakia [52] and Cyprus [53] .

Research concerts modelling dance sequence trajectories, which allows to digitalise and analyse the recorded movements. The results are often used for 3D modelling (e. g. Motion Builder) and in Virtual Reality technologies. Many research works on ICH present the process of implementing a tool for translating dance notation into 3D animation, focusing on the whole body, hand or only finger movements. Technologies used in dance studies are presented in Table 3.

Based on obtained 3D data, sophisticated methods like machine learning, long short-term memory network or Bayesian Optimized Bi-directional Long Short-Term Memory are used for classification and comparison of various types of dances [32].

A special digital data acquisition system has been developed that can preserve Japanese traditional dramas in the form of dynamic 3D models [54]. The traditional costumes of Japanese traditional dramatic actors consist of a long-sleeved costume and a fan. The proposed method of obtaining 3D models from the motion capture system allows the reconstruction of thin and long elements.

$\mathrm{ICH}$ is also presented in [55] in the form of the virtual Art Gallery of Shanghai Style Lacquerware. 3D laser scanning technology, 3D modelling technology and 3DMAX were applied.

\section{Storytelling studies}

Interactive digital storytelling is used to draw special attention to the historic items, places (e. g. Old Bridge in Mostar) [56, 57], events (e. g. the Chinese lantern festival) [58], myths [59] or arts [61]. For this purpose methods like VR, AR, 3D modelling or 3D visualisation are
Table 3 Technologies used in art studies

\begin{tabular}{ll}
\hline Papers & Technologies used \\
\hline Rallis et al. [32] & Motion capture, 3D modelling, 3D photogram- \\
Moulodimos et al. [33] & Motion capture, 3D modelling \\
Voulodimos et al. [34] & Motion capture, 3D modelling, 3D visualisation \\
Douka et al. [35] & Motion capture, 3D modelling, 3D visualisation \\
Ziagkas et al. [36] & Motion capture, 3D modelling \\
Ziagkas et al. [37] & Motion capture, 3D modelling \\
Rallis et al. [38] & Motion capture, 3D modelling, VR \\
Douka et al. [39] & Motion capture, 3D modelling, 3D visualisation \\
Rallis et al. [40] & Motion capture \\
Rallis et al. [41] & Motion capture, 3D modelling \\
Rallis et al. [42] & Motion capture, 3D modelling \\
Lim et al. [43] & Motion capture, 3D modelling \\
Xiang et al. [44] & Motion capture, 3D modelling, Motion Builder \\
Ribeiro et al. [45] & Motion capture, 3D modelling, VR \\
Tongpaeng et al. [46] & Motion capture, 3D modelling, VR \\
Tongpaeng et al. [47] & 3D modelling \\
Doulamis et al. [48] & Motion capture, 3D modelling, VR \\
Tongpaeng et al. [49] & 3D modelling, 3D visualisation \\
Tongpaeng et al. [50] & 3D modelling, 3D visualisation \\
Fu et al. [51] & Motion capture \\
Hajdin et al. [52] & Motion capture, 3D modelling, 3D visualisation \\
Stavrakis et al. [53] & Motion capture, VR \\
Rallis et al. [32] & Motion capture, 3D modelling \\
Hisatom et al. [54] & Motion capture, 3D modelling, 3D, photo- \\
Jl et al. [55] & grammetry \\
& 3D modelling, 3D scanning, 3D visualisation \\
\hline
\end{tabular}

used (Table 4). Additional techniques, applied together with the above mentioned, are audiovisual technologies, machine learning and natural language processing. This kind of combinations enabled users to visualise myths, artworks and their connections in comprehensible ways.

\section{Games-based learning studies}

Game-based learning is more and more often used for the virtual museums in order to raise culture awareness and motivate the public to visit cultural institutions [62]. Traditional skills and habits related to culture are documented by way of oral traditions and expressions. Game-based learning is also applied to dance choreography and posture analysis [40]. It is aimed at supporting the learning for promoting the protection of intangible culture (e. g. singing in Sardinia, St Andrews Cathedral) [65], explaining the cultural heritage to children [67, 69], explaining ancient technologies [68] or showing the connection between $\mathrm{ICH}$ and spatial geography [66]. Game-based learning is used for promoting singing, such as Human Beat Box [63] or Canto a Tenore [64]. In 


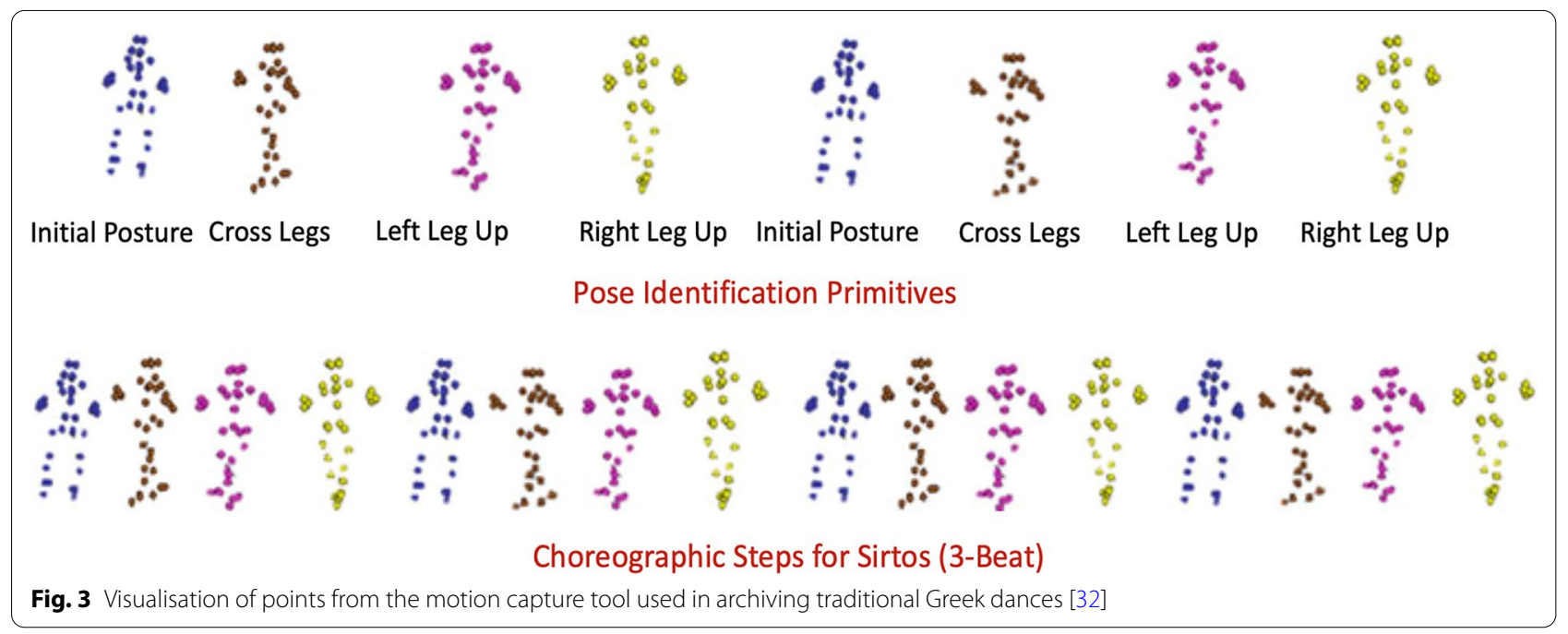

Table 4 Technologies used in storytelling studies

\begin{tabular}{ll}
\hline Papers & Technologies used \\
\hline Selmanovic et al. [56] & VR, AR \\
Rizvic et al. [57] & VR, 3D modelling \\
Shih et al. [58] & 3D modelling, 3D scanning, 3D visualisation \\
Yang et al. [61] & AR, 3D modelling \\
Thomopoulos [59] & 3D modelling, 3D visualisation \\
Selmanovic et al. [60] & VR, 3D modelling, 3D visualisation \\
Yang [61] & 3D modelling \\
\hline
\end{tabular}

Table 5 Technologies used in games-based learning studies

\begin{tabular}{ll}
\hline Papers & Technologies used \\
\hline Rallis et al. [40] & Motion capture \\
Cosovic et al. [62] & VR \\
Yilmaz et al. [63] & 3D modelling, 3D visualisation \\
Dagnino et al. [64] & Motion capture \\
Kennedy [65] & 3D visualisation \\
Bonenberger et al. [66] & VR, 3D GIS \\
Haddad et al. [67] & VR \\
Anastasovitis et al. [68] & VR, 3D modelling, 3D animation \\
Partarakis et al. [69] & VR, 3D modelling \\
Brusaporci [70] & 3D modelling, 3D visualisation \\
\hline
\end{tabular}

game-based learning studies various technologies are applied, like 3D modelling together with computer simulations, VR or 3D Geographic Information System (3D GIS) (Table 5). They allow to explain and explore how educational and multimedia heritage enables users to understand and appreciate cultural heritage [70].
Table 6 Technologies used in software studies

\begin{tabular}{ll}
\hline Papers & Technologies used \\
\hline Gaugne et al. [71] & 3D modelling, 3D photogrammetry, RTI \\
Hu et al. [72] & 3D modelling, 3D visualisation \\
Huang et al. [73] & AR, VR, motion caplture, Unity 3D \\
Yu et al. [74] & 3D modelling, Unity 3D \\
Dimitropoulos et al. [75] & Motion capture \\
Dagnino [76] & 3D visualisation, 3D modelling, AR \\
Cai et al. [77] & AR, 3D visualisation \\
\hline
\end{tabular}

\section{Software studies}

Software studies of ICH concerns many forms of research: music $[71,72]$, folk culture $[73,74]$, dance, singing, theatre, art [75, 76] and others [77]. The digitalisation allows an advanced analysis of the inscriptions and obtaining a complete and precise 3D models of the items. It is often further used to produce an interactive application. In software studies the following technologies are often used: 3D modelling (e.g. 3D MAX), 3D visualisation, 3D environment (e.g. Unity 3D), VR, motion capture systems and Reflectance Transformation Imaging (RTI) (Table 6). For the purpose of digital system studies a platform has been created, which is a new ground in education and knowledge transfer combining conventional learning procedures and sensorimotor learning through an interactive 3D environment (i-Treasure).

\section{Sport}

Sports are a key part of cultural identity and an important form of $\mathrm{ICH}$. An additional challenge in processing of sports data is the need to capture the context of the 
development of athletes' movement (together with their surroundings, including other objects, e.g. a ball) [7880]. In many studies (Table 7) the use of motion capture technology in conjunction with other 3D techniques (e.g. Zbrush software, Autodesk, MPEG-4) allows not only to reproduce the behaviour of athletes, but also to visualise their appearance or outfit. One of the possible ways to capture the relationship between objects is to use the in-between frame estimation method presented in Fig. 4.

\section{Settlement studies}

The aim of settlement studies is to aid the understanding and interpretation of ancient principles relating to sensitive and appropriate interaction of the built form and its associated landscape (e.g. First Nations) [81]. The principles have at their root the harmony of human

Table 7 Technologies used in sport studies

\begin{tabular}{ll}
\hline Papers & Technologies used \\
\hline Goenetxea et al. [78] & Motion capture, 3D visualisation \\
Arevalo et al. [79] & $\begin{array}{l}\text { Motion capture, 3D visualisa- } \\
\text { tion, 3D modelling }\end{array}$ \\
Linaza et al. [80] & Motion capture \\
\hline
\end{tabular}

inhabitation in the landscape they are surrounded by. A study of livelihood concerning the way of life based on environmental factors should also be taken into consideration [82-84]. To fulfil these aims the following technologies are usually used: 3D GIS, AR, 3D modelling and VR (Table 8).

\section{Other studies}

Despite the separation of previous research, there are articles that have been grouped as other studies. They concern a wide range of aspects of $\mathrm{ICH}$, such as: explore the artistic style [85], modelling design [86], preservation of culture [87-89], languages, signs and symbols [90], conservation of traditional painting methods [91], reconstruction of ancient items (e.g. flame lighting systems) [92-95] or acoustic properties of the buildings

Table 8 Technologies used in settlement studies

\begin{tabular}{ll}
\hline Papers & Technologies used \\
\hline Tang et al. [81] & 3D GIS \\
Jia et al. [82] & 3D modelling \\
Yang et al. [83] & $3 D$ GIS, AR \\
Xu et al. [84] & VR \\
\hline
\end{tabular}

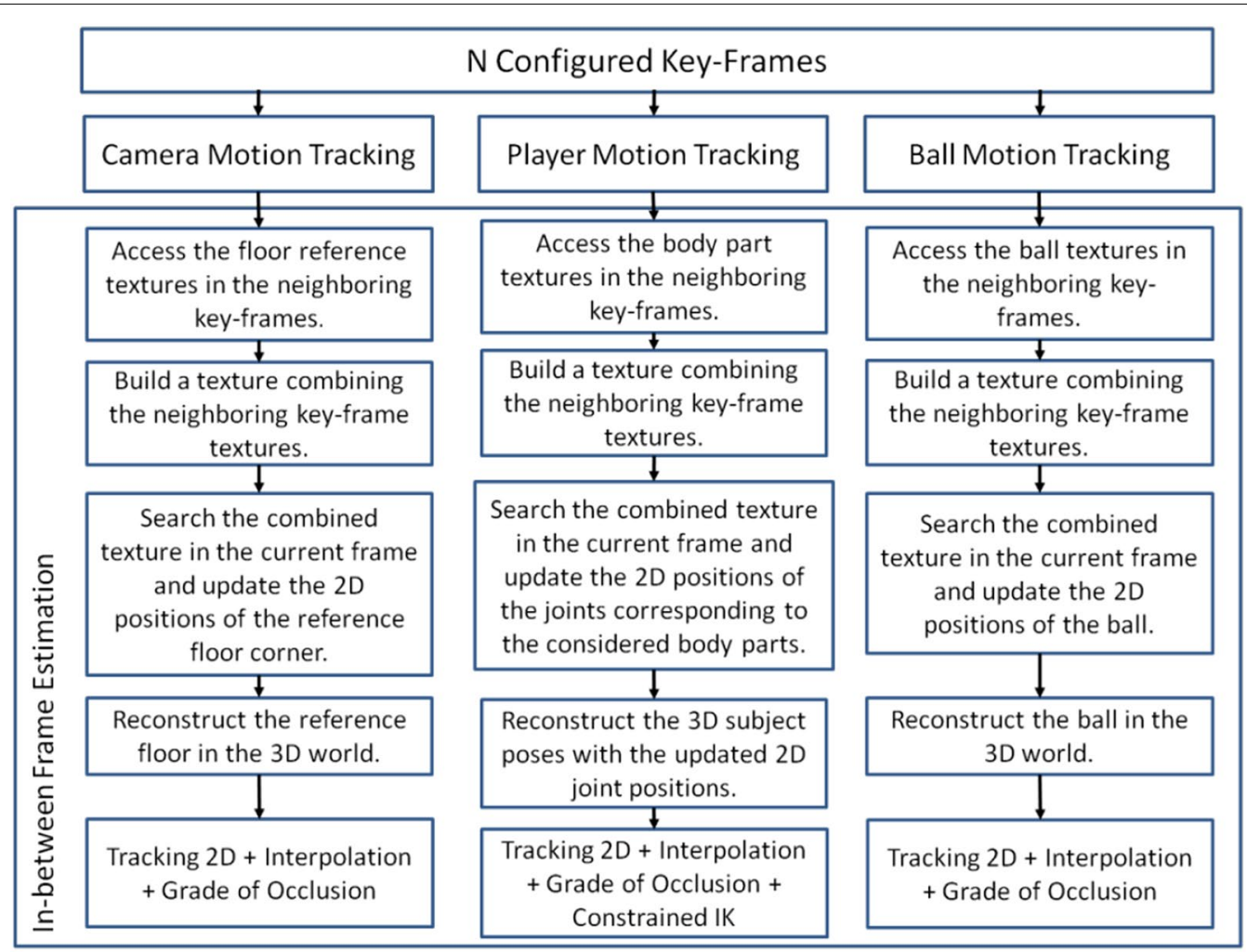

Fig. 4 An example of In-between frame estimation method [78] 
(e.g. theatre in Bologna, catholic cathedrals in Spain) [96-98]. These areas involve such technologies as: AR, 3D modelling, 3D photogrammetry, VR, 3D printing, RTI and 3D auralisation (Table 9). Together with the methods mentioned above, the following techniques are used: laser scanner, structure from motion, infrared radiation or infrared thermography.

\section{Mixed culture heritage}

A lot of studies focus on both material and non-material cultural aspects. They are closely related, complement and interpenetrate each other (Table 10).

\section{Architecture studies}

Many papers concern both $\mathrm{TCH}$ and $\mathrm{ICH}$. The arts integrated with historical analysis and iconographic sources are a perfect source of knowledge. The studies include historical architecture (e.g. Sant Marco Squere, Yuanming Yuan imperial Garden of the Qing Dynasty, Basilica of Sant'Ambrogio in Milan, churches and temples, Running Zhuma in Pizhou, Medieval Wall of Ávilath and others) [99-110]. They are extended by additional elements of culture such as: storytelling, the way of building monuments, headwear, clothing, music, soundscapes, spoken language, legends or interviews with inhabitants $[111,112]$. Typically, in studies focusing on $\mathrm{TCH}$ and $\mathrm{ICH}$, the following technologies are used: 3D modelling, VR, 3D visualisation, 3D auralisation, 3D GIS, motion capture, 3D photogrammetry or Light Detection and Ranging (LIDaR) (for large objects and sites) [113]. These methods are supported by Building Information Modelling (BIM), eXtended Reality (XR) and animation software (Autodesk, Maya 3D, Blender) in order to create

Table 9 Technologies used in settlement studies

\begin{tabular}{ll}
\hline Papers & Technologies used \\
\hline Yinfang et al. [85] & 3D modelling \\
Yang et al. [86] & AR, 3D modelling \\
Shi et al. [87] & VR, 3D animation \\
Zhang et al. [88] & VR, 3D GlS, 3D modelling \\
Dai et al. [89] & VR, 3D modelling \\
Parrinello et al. [90] & VR, 3D modelling \\
Jung et al. [91] & Capture system \\
Li et al. [92] & 3D modelling, 3D visualisation \\
Lassandro et al. [93] & 3D modelling, 3D photogrammetry, 3D \\
Griffo et al. [94] & visualisation \\
Gao et al. [95] & 3D photogrammetry, 3D modelling, RTI \\
Manfren et al. [96] & 3D modelling, 3D visualisation, 3D printing \\
Alvarez-Morales et al. [97] & 3D auralization, 3D modelling \\
Xu et al. [98] & 3D auralization \\
\hline
\end{tabular}

Table 10 Technologies used in architecture studies for mixed culture heritage

\begin{tabular}{ll}
\hline Papers & Technologies used \\
\hline Wang et al. [99] & 3D modelling, VR, 3D visualization \\
Banfi et al. [100] & 3D photogrammetry, 3D modelling, VR \\
Themistocleous et al. & 3D visualization \\
$\begin{array}{l}\text { [101] } \\
\text { Xue et al. [102] }\end{array}$ & 3D modelling, 3D visualization \\
Sanchez-Aparicio et al. & 3D modelling, 3D visualization \\
[103] & \\
Thomas et al. [104] & 3D modelling, 3D visualization \\
Cao et al. [105] & 3D modelling, 3D visualization, VR \\
Mallik et al. [106] & Motion capture, 3D visualization \\
Mallik et al. [107] & Motion capture, 3D visualization \\
Chroni et al. [108] & 3D GlS, VR, 3D modelling \\
Tan et al. [109] & 3D auralization \\
Balletti et al. [110] & 3D modelling, 3D printing, 3D photogrammetry \\
Kitsikidis et al. [111] & Motion capture, 3D visualization, 3D modelling \\
Liu et al. [112] & 3D modelling \\
Rodriguez-Gonzalvez & LIDaR \\
et al. [113] & \\
\hline
\end{tabular}

interdisciplinary research. The methodology for creating AR using a big scene consisting of buildings, characters, tools and object is presented in Fig. 5.

\section{Settlement studies}

The settlement studies for a mixed type of culture concern historical sites (e.g. Zandieh Complex and Hafezieh Tomb) [114] as well as detection of the new archaeological places, digital repository about movable, stationary and immaterial heritage (e.g. the Danube region) [115], migrations (e.g. Paths of Roman Routes-Via Traiana in Italy, Via Egnatia in Albania, and Via Flavia in Albania and Montenegro) [116], memories and legends (e.g. the Ogiek people) [117] and reconstruction of behaviour of ancient people $[118,119]$. They are often extended with the use of 3D objects, films, texts, photos and descriptions for better culture understanding. For the purpose of the study the following technologies are commonly used: 3D modelling, 3D GIS, 3D visualisation, VR, AR, 3D photogrammetry or LIDaR [120] (Table 11). They enables the interaction of visitors with a variety of informational content.

\section{Museum studies}

Another group of study is related to museum collections which are presented in a form of virtual exhibitions [121]. Artworks are characterised by intangible and historical values, such as heterogeneous documentary heritage that enlightened the need of creating new narratives while avoiding the descriptive and analytical ones [122]. For 


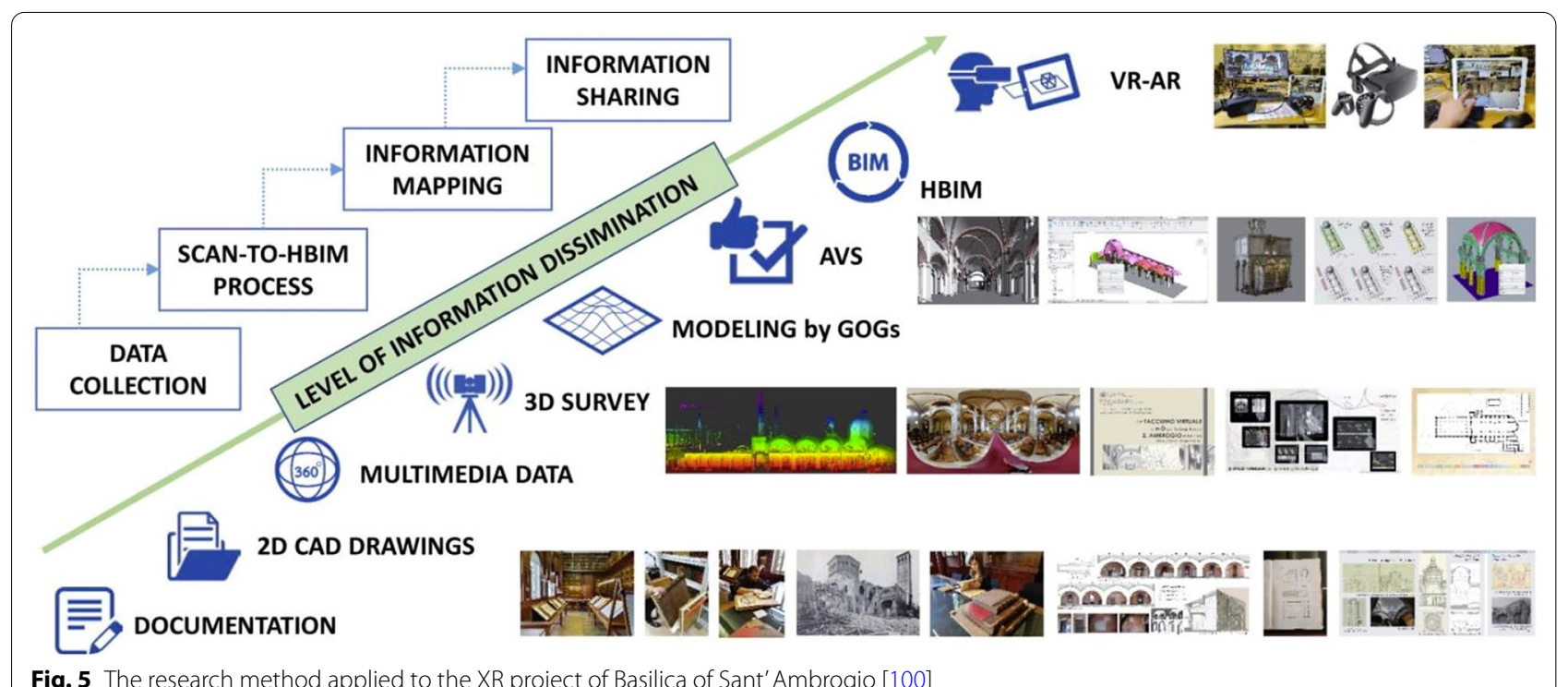

Table 11 Technologies used in settlement studies for mixed culture heritage

\begin{tabular}{ll}
\hline Papers & Technologies used \\
\hline Chizfahm et al. [114] & 3D modelling \\
Zakrajsek et al. [115] & 3D GIS \\
de Fino et al. [116] & 3D GIS, 3D visualization, VR, AR \\
Rambaldi et al. [117] & 3D modelling \\
Cheng et al. [118] & VR, 3D modelling, 3D visualization \\
Yang et al. [119] & VR, 3D photogrammetry, 3D modelling \\
Coren et al. [120] & LIDaR \\
\hline
\end{tabular}

the purpose of the museum study the following technologies are commonly used: 3D modelling, VR, 3D photogrammetry and motion capture (Table 12). The created applications (mobile or web) are often based on specific frameworks (e.g. 3D Heritage Online Presenter). The paper's aim is to improve the users' view during their visits in the virtual museum [123].

\section{Software studies}

Many papers related to digital system studies are based on creating a platform consisting of websites, available from a smartphone, where sightseers can read the narrative or download various materials useful during a visit to specific places as well as information about cultural events [124-130]. In this way, tourists can easily access the cultural content, choosing the communication format they prefer supported by the technology they have. Another group of applications is implemented for
Table 12 Technologies used in museum studies for mixed culture heritage

\begin{tabular}{ll}
\hline Papers & Technologies used \\
\hline Wang et al. [121] & 3D modelling, VR, 3D photogrammetry \\
Lo Turco et al. [122] & 3D modelling, 3D photogrammetry, 3D visualization \\
Lil et al. [123] & Motion capture, 3D visualization, VR \\
\hline
\end{tabular}

Table 13 Technologies used in software system studies for mixed culture heritage

\begin{tabular}{ll}
\hline Papers & Technologies used \\
\hline Pietroni et al. [124] & 3D modelling, AR \\
Arias-Espinoza et al. [125] & 3D modelling, AR, 3D visualization \\
Medina-Carrion et al. [126] & 3D modelling, AR, 3D visualization \\
Viinikkala et al. [127] & AR, VR \\
Wen et al. [128] & AR, 3D modelling \\
Medici et al. [131] & 3D scanning \\
Munster et al. [132] & 3D modelling \\
Pettoello et al. [135] & VR, 3D visualization \\
Wu et al. [133] & 3D modelling \\
Adabala et al. [134] & AR \\
Damiano et al. [136] & 3D modelling, 3D visualization \\
Banfi et al. [129] & 3D modelling, AR, VR \\
Ermrnyi et al. [130] & 3D scanning, 3D modelling \\
Medici et al. [131] & 3D scanning \\
Munster et al. [132] & 3D modelling \\
Wu et al. [133] & VR \\
Adabala et al. [134] & AR \\
Pettoello et al. [135] & VR \\
Damiano et al. [136] & 3D modelling, 3D visualization, VR \\
\hline
\end{tabular}


educational purposes to support both teaching and rescuing the socio-cultural heritage [131-133]. The studies also include virtual libraries and platforms supporting 3D reconstruction. Another type of applications concerns the interactive multimedia frameworks for digital heritage narratives and storytelling as well as designing the user interface and the appearance of 3D model showing the described intangible heritage [134]. Applications dedicated to specific actions such as virtual archaeology or ontology are also created $[135,136]$.

To meet the requirements of software studies, the following technologies are usually used: 3D modelling, AR, VR, 3D visualisation and 3D scanning (Table 13). They allow to create intangible intellectual foundation, creative abilities, cultural identity and history, which are based on digital expressions of culture and identity.

\section{Results}

Quantitative analysis

See Tables 14, 15, and Fig. 6.

\section{Detailed results}

See Figs. 7, 8, 9, 10, 11, 12, 13, 14, 15 and 16.

Geographic, technological and product cross-section

See Tables 16 and 17, Figs. 17 and 18.

\section{Discussion}

In this paper a multi-aspect analysis of 3D technologies in the aspect of both $\mathrm{ICH}$ and mixed $\mathrm{CH}$ is performed. In Table 14 the number of searched studies for the following TITLE-ABS-KEY text: cultural AND (intangible OR non-material) AND heritage AND ( $3 D$ OR three-dimensional OR "three dimensional") is shown. The papers to which there was no access in their entirety or which

Table 14 Analysed papers in the following databases in years 2005-2021

\begin{tabular}{llll}
\hline & $\begin{array}{l}\text { Searched } \\
\text { papers }\end{array}$ & $\begin{array}{l}\text { Excluded } \\
\text { papers }\end{array}$ & $\begin{array}{l}\text { Included } \\
\text { papers }\end{array}$ \\
\hline Scopus & 151 & 40 & 111 \\
Web of Knowledge & 113 & 23 & 90 \\
IEEE Xplore & 41 & 15 & 26 \\
\hline
\end{tabular}

Table 15 Papers of tangible and intangible types for three databases

\begin{tabular}{lllc}
\hline & Scopus & Web of knowledge & IEEE xplore \\
\hline TCH & 12 & 19 & 4 \\
ICH & 64 & 46 & 14 \\
Mixed $C H$ & 35 & 25 & 8 \\
\hline
\end{tabular}

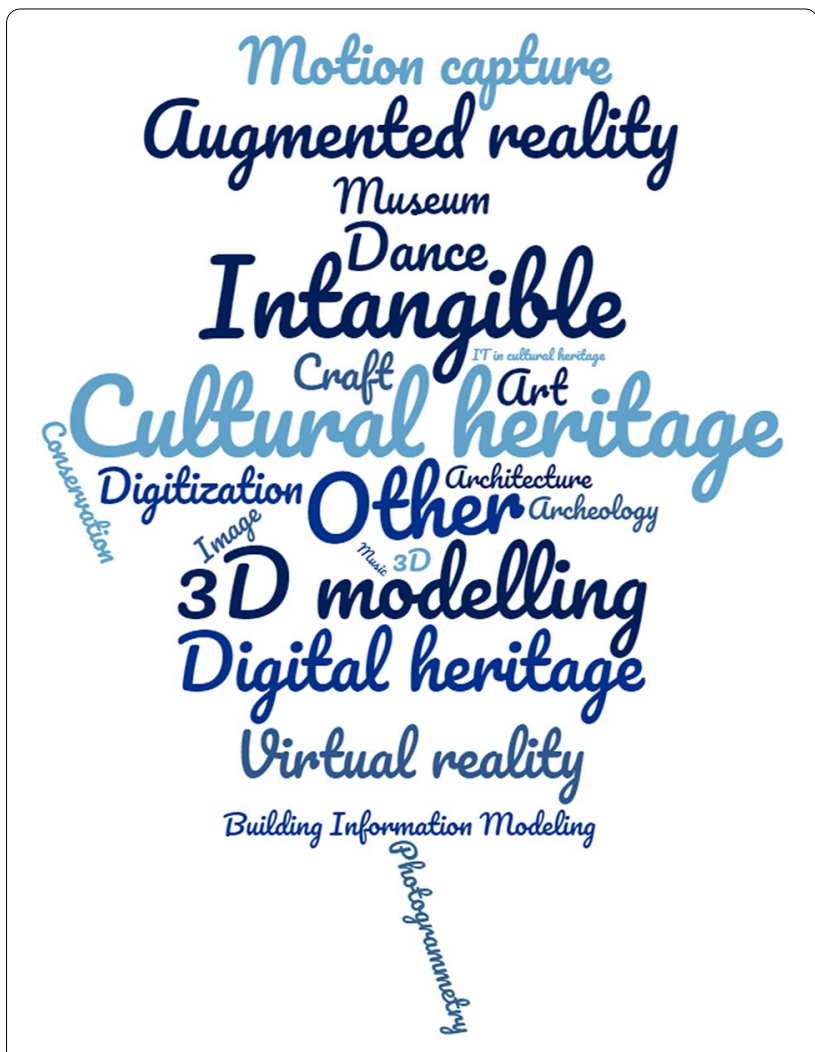

Fig. 6 The cloud of given keywords in ICH papers

did not cover the specified topics of 3D technology or culture heritage were not taken into further consideration. Totally, 132 papers were considered for the analysis (Table 15). The first database, Scopus, contains the greatest amount of papers in this area (111). All papers searched in IEEE Xplore coincided with those in the Scopus database. 21 papers were found in the Web of Knowledge that were not in other databases.

The most popular 3D technologies used in $\mathrm{ICH}$ are (respectively): 3D modelling, motion capture, 3D visualisation, VR and AR. They constitute almost $86 \%$ of all technologies in the analysed publications (Tables 2, 3, 4, 5, 6, 7, 8 and 9). On the other hand, in mixed $\mathrm{CH}$, the most commonly used 3D technologies turned out to be (respectively): 3D modelling, 3D visualization, VR and AR. They constitute almost $68 \%$ of all technologies in the analyzed publications (Tables 10,11, 12 and 13).

3D model generation of artifacts, monuments or large environments is nowadays often used in scientific studies. 3D modelling is based on photographs and geometric projections according to architectural criteria [138]. It allows to create a digital representation of an object in three dimensions using dedicated software (e.g. Unity 3D, Maya, Auto CAD, 3D Studio Max). The most important advantages of 3D modelling include: easy to 


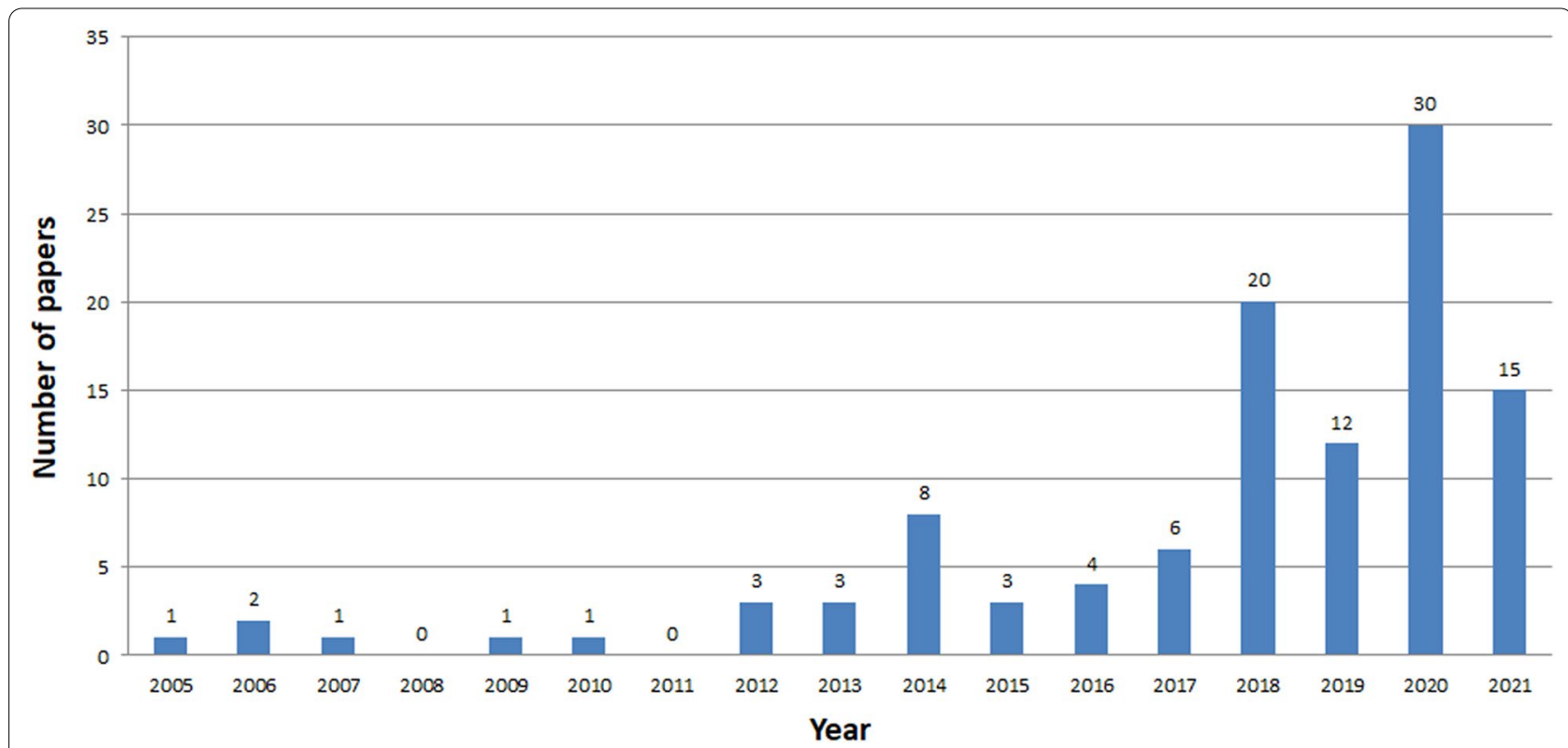

Fig. 7 Number of ICH papers in Scopus in years 2005-2021

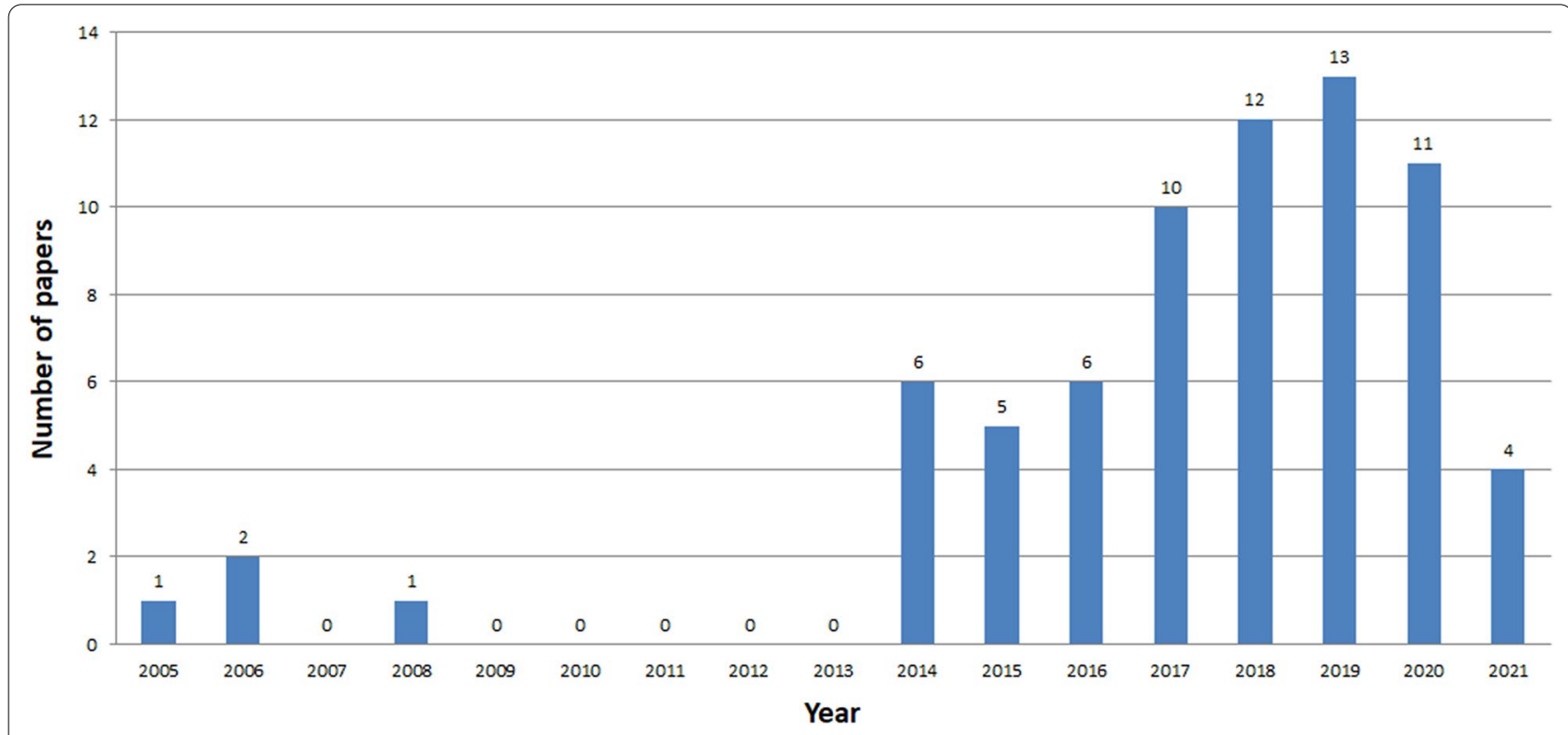

Fig. 8 Number of ICH papers in Web of Knowledge in years 2005-2021

use tools with mathematical models, which does not require too much training, the possibility to work with complex items convenient for many types of objects and used in VR and AR as well as open-source software availability. Among the disadvantages of 3D modelling are the facts that it is not always possible to obtain fully natural shapes, it requires large computational resources and processing of complex models needs the use of commercial software. Nowadays 3D models must reach a sufficient level of realism and accuracy [137]. 3D modelling is applied in many fields: e. g. entertainment, gaming, $\mathrm{ICH}$ and $\mathrm{CH}$.

$3 \mathrm{D}$ visualization is closely related to modelling. It makes possible for the analysts to gain a deeper, more intuitive understanding of the models. The development of Information Technology (IT) tools make it 


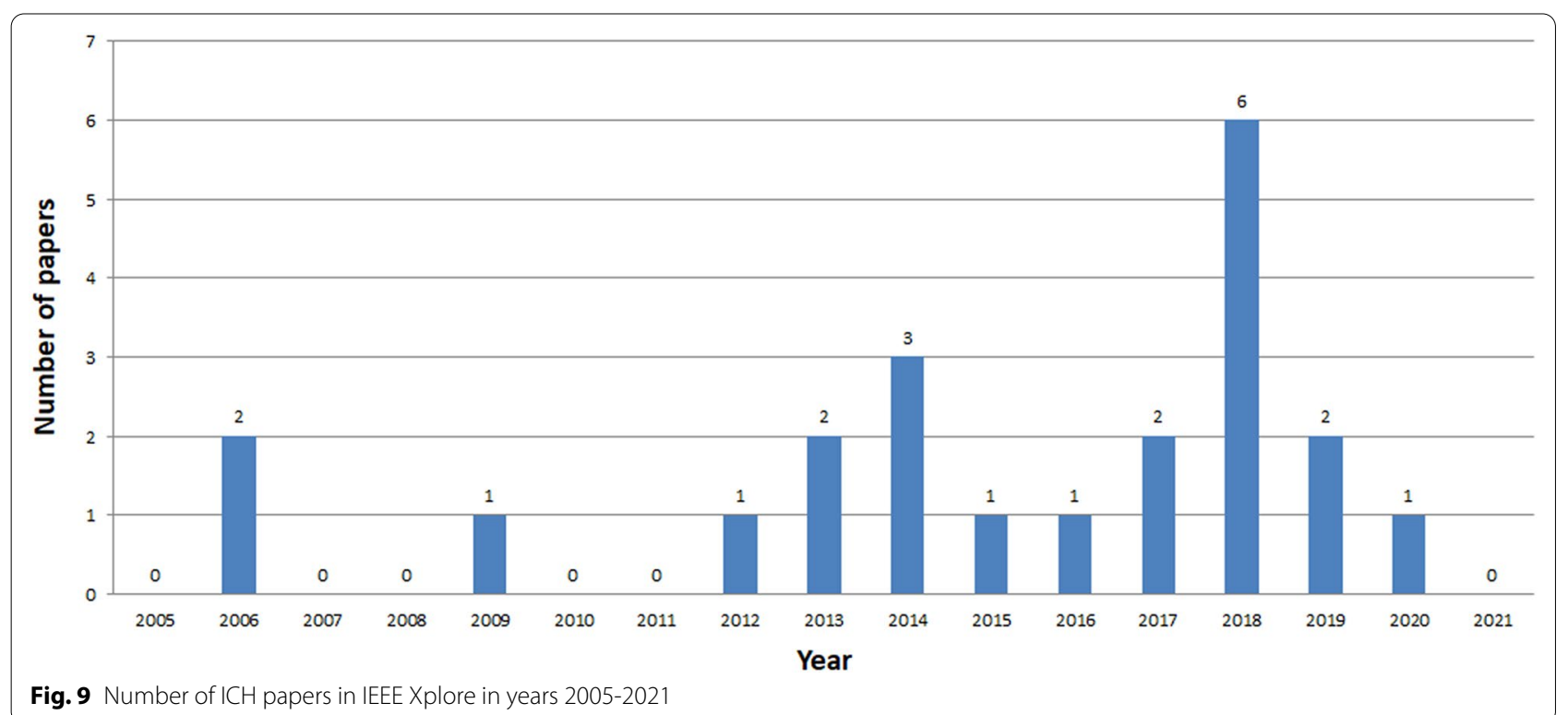

Fig. 9 Number of ICH papers in IEEE Xplore in years 2005-2021

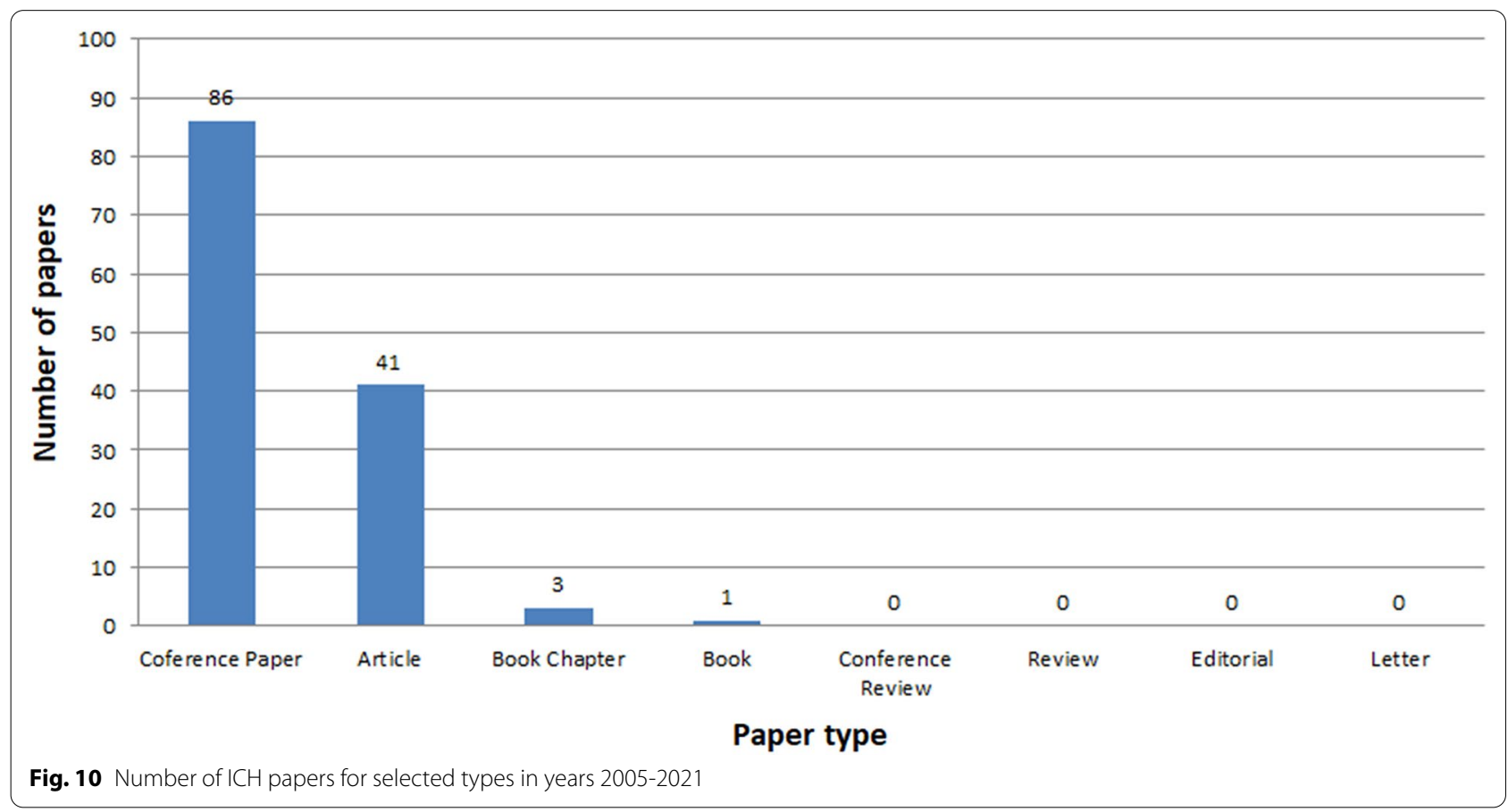

possible to present 3D models. Nowadays, non destructive techniques for creating $2 \mathrm{D}$ and $3 \mathrm{D}$ digital data become more and more useful for investigating $\mathrm{ICH}$ [138]. The visualization system should be able to display the field measurements and verification of 3D physical units. WebGL, GL Scene, OpenGL, Cesium JS, Google Earth, Computer-aided design (CAD), BIM or 3D map are commonly used visualisation platforms. 3D object management is possible through a dedicated user interface [139]. 3D visualization greatest advantages include: ease of implementation on platforms with raster graphics, precise and accurate rendering, ease of its distribution. The disadvantages of 3D visualization include: problems with implementing perspective and texture, expensive processing, difficulty in defining image depth. Reality-virtuality relationship, which integrates the most commonly used technologies in $\mathrm{ICH}$, from the creation of $2 \mathrm{D}$ and $3 \mathrm{D}$ models, thought 

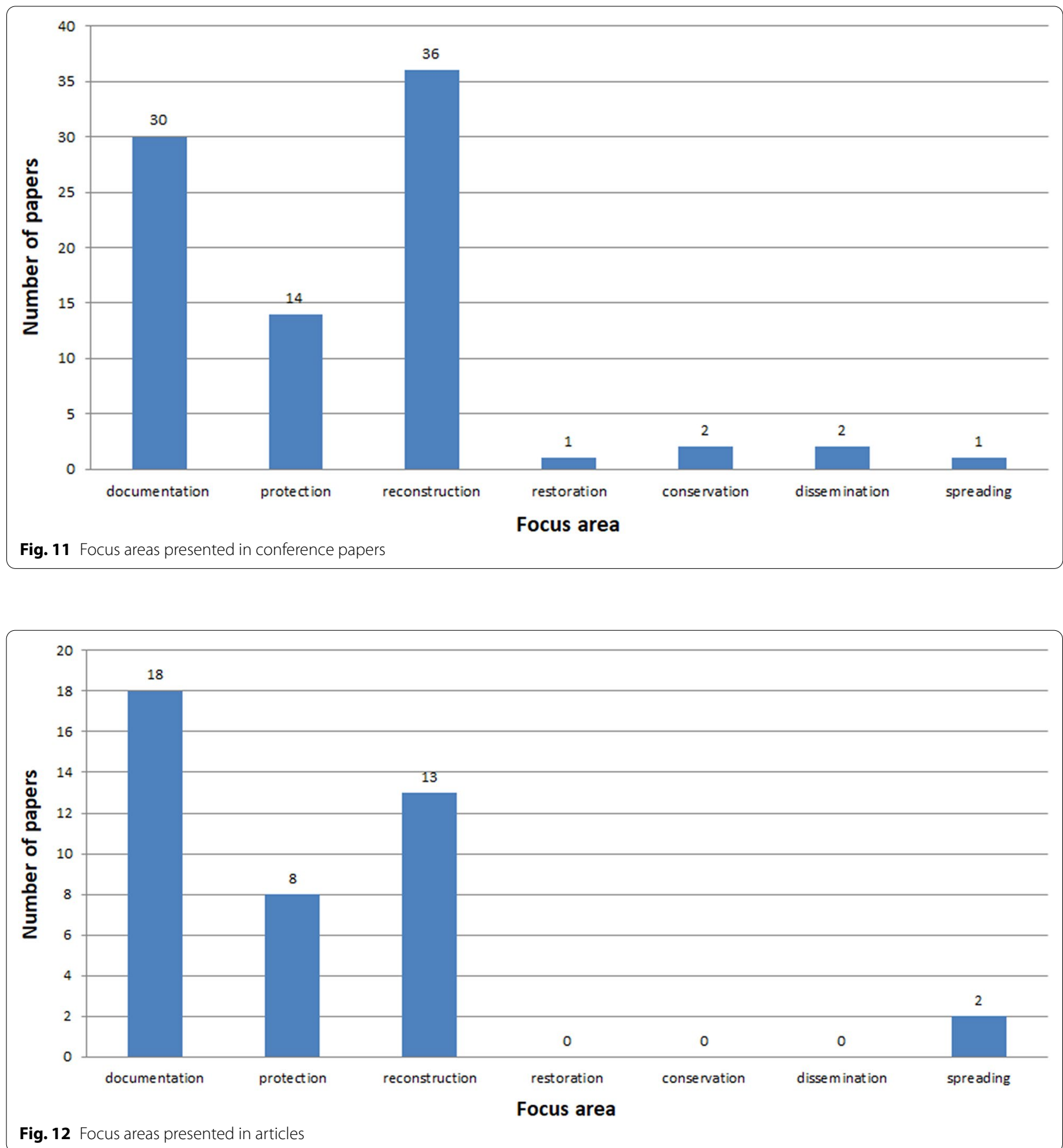

their visualisation as well as the creation of AR and VR applications, is presented in Fig. 19. AR applications are located closer to the real world, while the virtual world is represented by VR solutions.

$A R$ is a technology that combines the interactive real world with an interactive computer-generated world in such a way that they together appear as one environment
[140, 141]. It means that the user moves around the real object, while the virtual ones react in a way as it is integrated with the real world. The virtual object may move but they should reflect real-world movement rules.

The classification of AR systems may refer to many criteria, such as: hardware (e.g. the type of tracking system), visualisation approaches (see-through, video-mixture) 

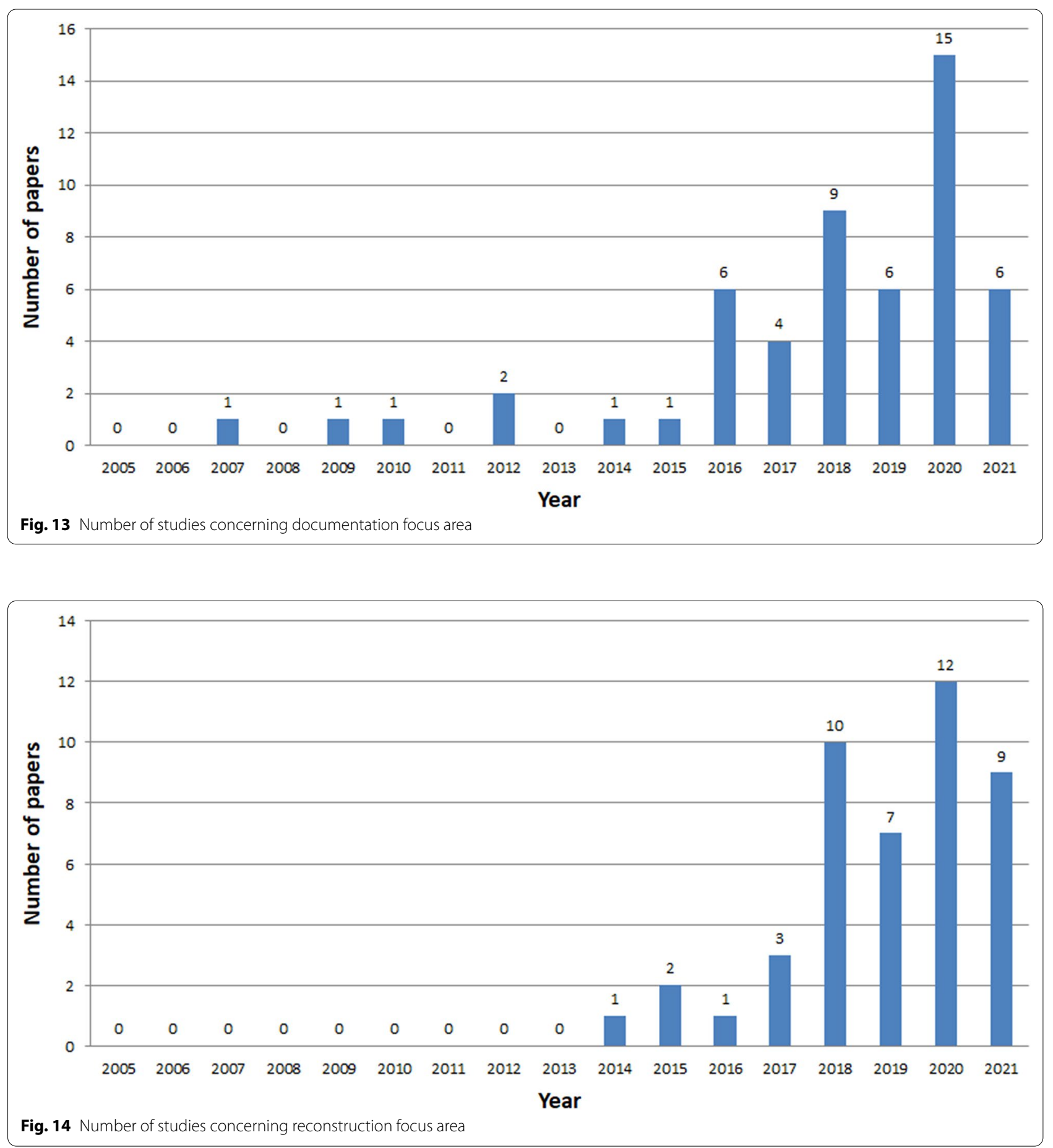

or working distance (indoor, outdoor), communication (wireless, hardwired) [140]. Indoors systems use static markers that are attached to visible parts. They are limited to small 3D models, number of images or size of the user path. Outdoors system are based on markers that exist in the real world. The weather and its changes (e.g. sun shinning or shadows) is one of the biggest problems in this type of applications. Indoor systems provide accuracy of a few centimetres while outdoor ones need to use absolute or relative positioning systems, in combination with vision systems when the accuracy is not sufficient. Outdoor applications usually need a special transmission channel, which either has to be developed or existing communication services have to be used [140, 141]. 

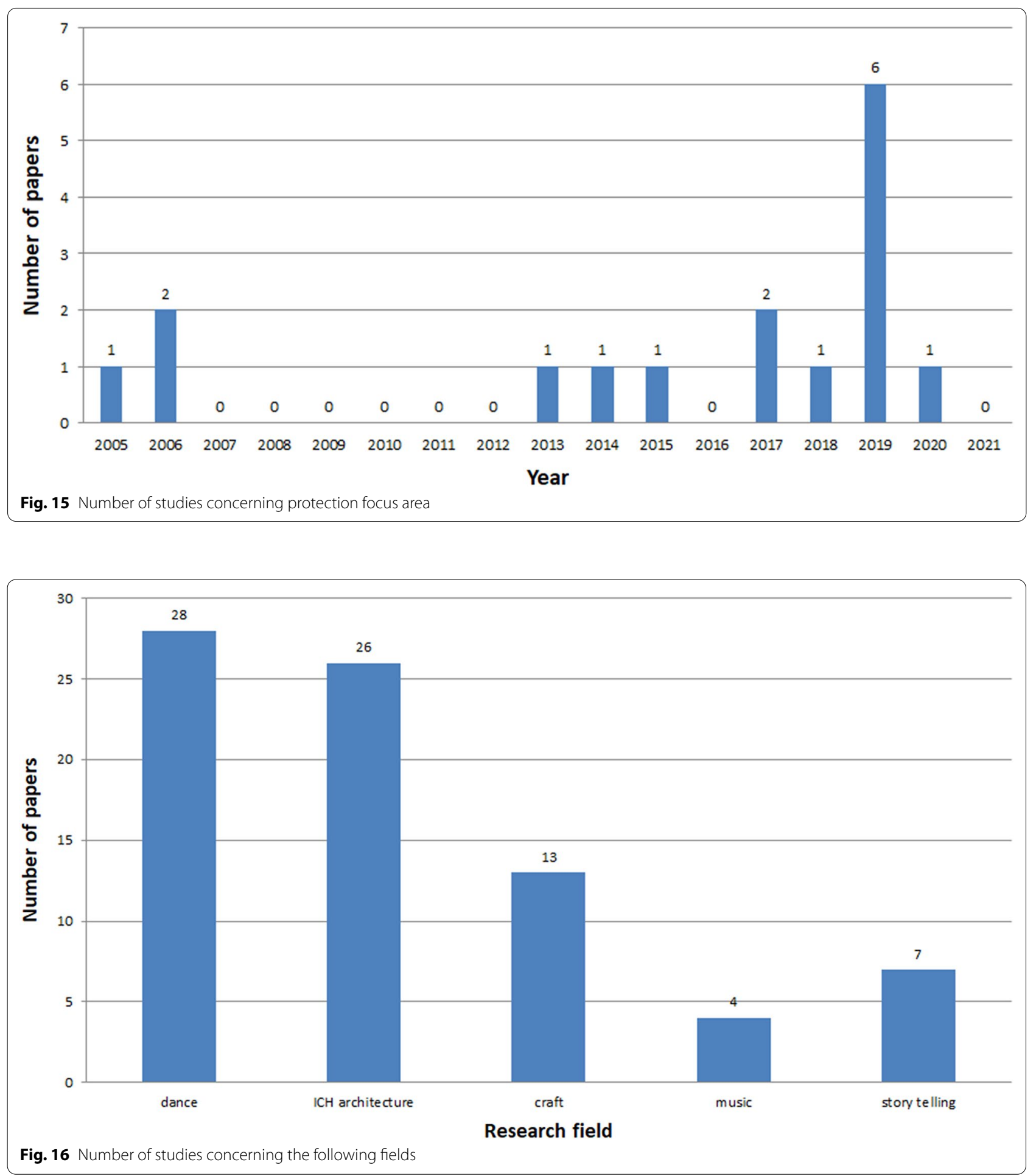

VR is a modern technology that enables transfer to a virtual world that allows users to represent various elements, including culture. It may be defined as a way for humans to visualise, manipulate and interact with computers and complex data [140]. It consists of two important issues: the world (usually 3D) and an appropriate level of interaction with realism. VR systems may be classified based on [140]: hardware (from desktop equipment to spatially immersive systems, e.g. CAVE) and display system (from observing the screen, to being inside 


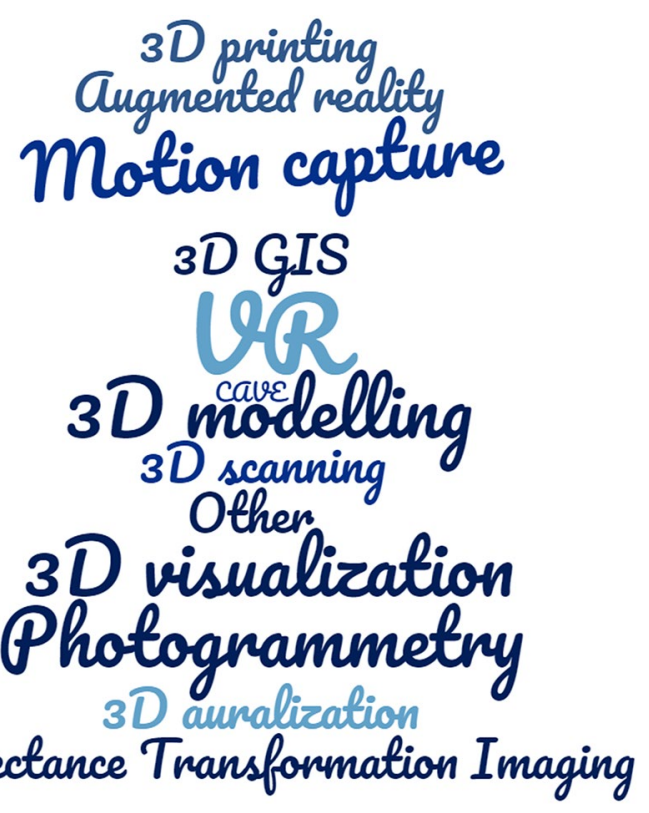

Fig. 17 The cloud of 3D technologies used in the papers concerning intangible heritage

Table 17 Number of studies for the specified aims

\begin{tabular}{lll}
\hline Aim of the study & Number of papers & Percentage [\%] \\
\hline Education & 41 & 17.67 \\
3D models & 36 & 15.52 \\
Promoting heritage & 33 & 14.22 \\
Learning & 20 & 8.62 \\
Virtual Reality & 15 & 6.47 \\
Recognition & 17 & 7.33 \\
Visual reconstruction & 18 & 7.76 \\
Identify the differences & 11 & 4.74 \\
Entertainment & 15 & 6.47 \\
Assessment & 8 & 3.45 \\
Create artwork & 8 & 3.45 \\
Analysis & 4 & 1.72 \\
Virtual tours & 5 & 2.16 \\
Storytelling & 1 & 0.43 \\
\hline
\end{tabular}

the VR environment) or both. Another type of classification is the type of simulation: pure geometry (lines, points, geometric shapes), static semantics (realistic complex static objects) and dynamic semantics (dynamic objects). These systems may be also divided based on the way data is displayed, such as: single frames, sequence of frames (animation), or real-time work. Interaction, which ranges from none to full immersion, indicates the special high level hardware equipment used (e.g. CAD or GIS). VR systems generally track the motion of hand-held objects or a user's head or limbs, and the received data is used to determine the user's view, navigation, interaction with objects, and possible movement of a virtual body [142]. One of the problem that VR needs to update the 3D imagery in real-time presents obvious challenges that have limited the ability to reproduce complex phenomena such as light refraction [142]. Another issue is eliminating latency, which requires to respond to the user's movements in milliseconds.

Motion capture is a widely-used technique for capturing movements for digital processing. It can be divided for mechanical, magnetic and optical ones [143]. Mechanical systems use an exoskeleton consisting of encoders that record the rotation of individual joints. Based on the calculated values and positions of the encoders, computers determine the movement of a person. These systems are not limited by space or the number of cameras. However, the exoskeleton limits the movements of the

Table 16 Studies referring to countries

\begin{tabular}{|c|c|c|}
\hline Country & $\begin{array}{l}\text { Number of } \\
\text { countries } \\
\text { affiliation }\end{array}$ & $\begin{array}{l}\text { Number of countries } \\
\text { referred to in studies }\end{array}$ \\
\hline China & 36 & 31 \\
\hline Greece & 29 & 23 \\
\hline Italy & 22 & 13 \\
\hline Bosnia and Herzegovina & 7 & 4 \\
\hline USA & 6 & 1 \\
\hline Spain & 4 & 3 \\
\hline India & 4 & 3 \\
\hline Thailand & 4 & 4 \\
\hline Turkey & 4 & 0 \\
\hline Japan & 5 & 4 \\
\hline France & 2 & 2 \\
\hline The Netherlands & 2 & 1 \\
\hline Ecuador & 2 & 0 \\
\hline Korea & 3 & 3 \\
\hline Hong Kong & 1 & 0 \\
\hline Canada & 2 & 0 \\
\hline Czech Republic & 1 & 0 \\
\hline Slovenia & 1 & 0 \\
\hline Lithuania & 1 & 0 \\
\hline Portugal & 1 & 0 \\
\hline Finland & 1 & 1 \\
\hline Belgium & 1 & 0 \\
\hline Switzerland & 1 & 0 \\
\hline Germany & 1 & 0 \\
\hline Ireland & 1 & 1 \\
\hline Cyprus & 1 & 1 \\
\hline Romania & 0 & 1 \\
\hline Canari & 0 & 2 \\
\hline
\end{tabular}




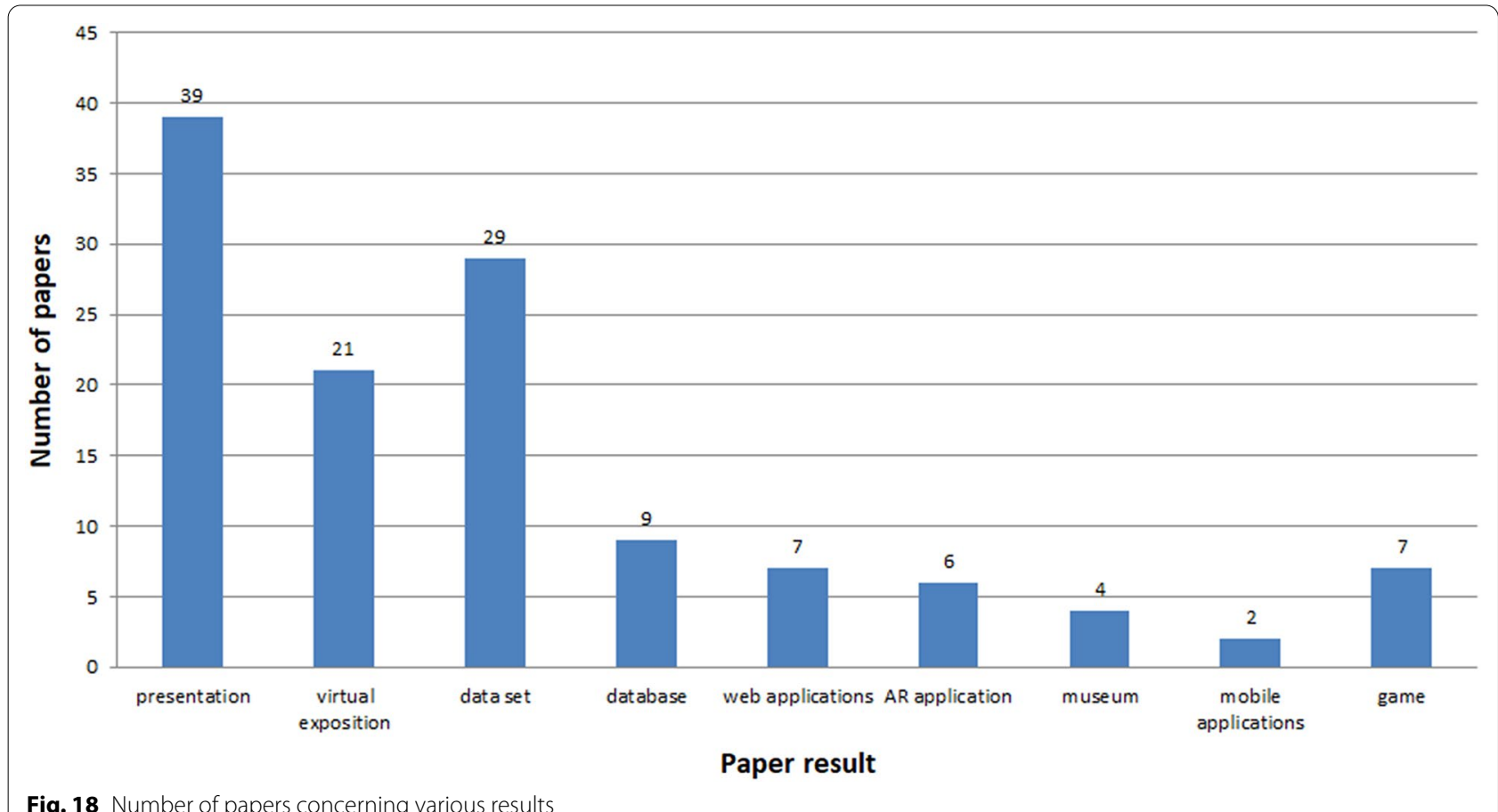

Fig. 18 Number of papers concerning various results

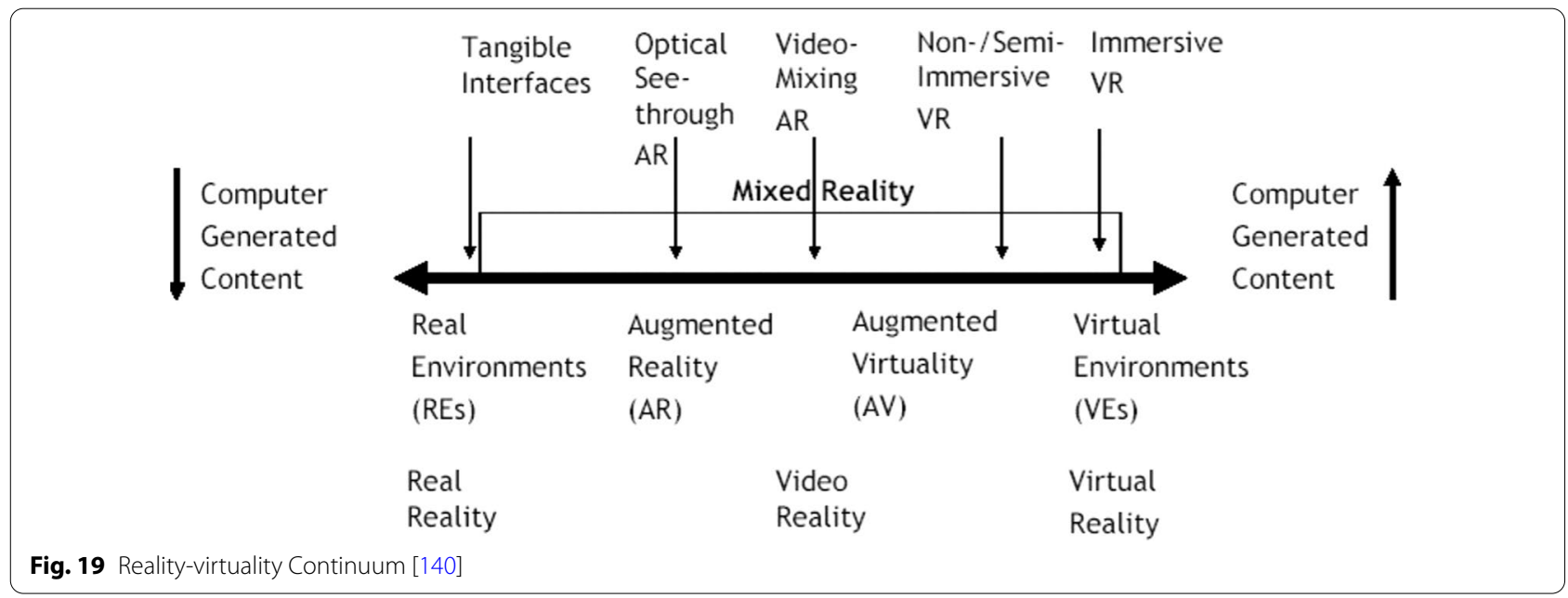

reordered persons. The accuracy of movement capturing depends on the encoders position and modelling of the skeleton. Magnetic motion capture is done through a field of electro-Magenta in which sensors are electrics. The optical motion capture systems consist of synchronized cameras that register the movement. They can be divided on these with and without markers (markerless). They register movement in 3D coordinate system. The cameras send signals which are reflected from the markers and which returned to the sources. Visibility of markers by at least two cameras ensures indicating a position of the marker in space. The minimum frequency of the recorded motion is $45 \mathrm{~Hz}$. However, for the more dynamic movements the higher frequency should be set, at least $100 \mathrm{~Hz}$. The big disadvantage of these systems is that the markers may disappear from the video while they are covered during movement. That is why, the positions of these markers are then interpolated during post-processing which is usually time-consuming. An example of a markerless system is the Kinect sensor, which records movement in 2D coordinate system [144]. The slower Kinect sensor has a sampling frequency of $30-37 \mathrm{~Hz}$, and 
insufficient smoothing algorithms may have contributed to inability to properly capture the flexion and extension peak amplitudes. They are less accurate in relation to the optical systems based on markers, but they are also much cheaper and commonly used in scientific research.

It has to be assumed that all above presented technologies may be integrated for ICH purposes (Tables 2, 3, 4, 5, $6,7,8,9,10,11,12$ and 13).

The first aspect of presented analysis covers the specified keywords in ICH papers (Fig. 6). Cultural heritage, specified as a keyword, was returned in the greatest number of studies. It is the most general term that corresponds to both $\mathrm{TCH}$ and $\mathrm{ICH}$ areas. The next keyword with a high frequency of occurrence is intangible, which limits the discussed type of cultural heritage. Used in studies, 3D technologies are also often given as keywords. In the analysis carried out, the most common were: 3D modelling, AR and motion capture system. They are up to date technologies that have found their application in this niche field. Dance was listed as one of the most common keywords. This means that it is one of the key elements of 3D ICH and has been recognised as an essential archiving knowledge for future generations.

The analysis clearly shows that the interest in $\mathrm{ICH}$ is growing year by year, starting from 2014 (Figs. 7, 8, 9). The exception is a slight decline in interest in 2019 in the Scopus database, and in 2020 in the Web of Knowledge. This may be due to the inability to conduct studies due to COVID-19. The process of review may also be time consuming. The least results are found in IEEE Explore. Since 2018 only a few papers have been stored. Papers concerning ICH have started appearing in small numbers since 2005 . The decline in interest in publishing in 2007-2013 is clearly visible. The greatest amount of papers were published between 2018 and 2020.

The vast majority of all papers are published as conference papers and journal articles (Fig. 10), whereas the articles make up half of the conference papers. ICH is a developing field of science where a great amount of the studies is published at various conferences. One reason for this is that the initial results are sent for conferences. The more sophisticated ones are published in journals. Analysis of conference papers shows that the authors largely present topics related to three areas: documentation, reconstruction and protection (Figs. 11, 12). Papers concerning issues related to restoration, conservation, dissemination and spreading are in a minority. A similar tendency is maintained in the works appearing in thematic journals. Here, also, the greatest emphasis is put on documenting ICH (Fig. 12). However, there were a few issues related to restoration, conservation, dissemination, and the number of works deals with spreading is 2 .
The documentation area consists of various aspects of ICH: music [71, 96], tuna fishing [19], crafting [20, 21] storytelling [57, 60, 121], visualisation of historical sites in Iran [114], Art Gallery of Shanghai Style Lacquerware [55], capturing dance [33, 34, 40, 41, 111], art [110], virtual exhibitions [62, 99, 100, 105, 145], 3D models [94, $146]$ and settlement $[147,148]$. Oral interpretations and their expressions are also one of ICH type. They are used in game-based learning in virtual museums to document culture and encourage visitors to expand their knowledge in this area [62].

The reconstruction of various $\mathrm{ICH}$ items include: museums [3], traditional folk dances [35, 36, 49, 50, 52, 111], traditional crafts which contains a lot of valuable information on how ancestors made objects, which are forgotten by successive generations is presented in [23, 72]. 3D technology allows to present ancient festivals and is unique in ICH: Lantern Festival [58], "Noh" and "Kabuki" [149]. The virtual reconstruction of the ancient internal flame lighting systems is presented in [93]. The research was used for defining the lighting scenarios according to various historical-interpretative hypotheses and for reconstructing of the luminaires. The reconstruction of ancient buildings are described in [102, 103, 122, $125,126,150]$, ancient routes in [116] and ancient art of war in [151].

In [95] the application and research in ICH Quanzhou marionette protection is described. Based on the folk intangible cultural heritage centre the interactions were created to protect ICH [73]. Other studies which concern protection topic are presented in $[3,30,112,118,119$, $149,152]$.

The most applied focus areas, documentary, protection and reconstruction were divided into the years of the publication (Figs. 13, 14 and 15). The studies concerning protection started in 2005, the documentary in 2007 and the reconstruction in 2014. The most papers were published in the years 2016-2020. It means that intangible heritage is a developing field of study.

Analysing the aspects described in the papers, it can be stated that there are two very important issues of the human culture: dance and $\mathrm{ICH}$ aspects of architecture (Fig. 16). It has been noticed that these aspects of $\mathrm{ICH}$ culture are highly important, up to $73 \%$ of all studies. It seems that these two fields of study have a great potential. Due to sophisticated modern technologies dance may be modelled and its intangible aspects passed down to future generations. It should be emphasized that these fields of study also appear in other types of papers concerning software, game-based learning and others. In the analysed studies the most important technologies are: VR, 3D modelling, 3D visualisation, motion capture and Photogrammetry (Fig. 17). 
The greatest amount of studies is performed in China, Greece and Italy. These studies are done by the domestic and foreign researchers in multi-disciplinary groups. These are countries with a great potential of culture. The aims of the studies vary (Tables 16 and 17). However, the most common purpose was education (17.67\%), creation of 3D models (15.52\%) and promotion of heritage (14.22\%). An important issue was the element of learning and VR creation (Figs. 18, 19).

Many models have been created using different tools and formats concerning cultural heritage. In 2013, an attempt was made to formalise the data for cultural heritage, which is presented in paper [153]. A generic, extendable and interoperable framework for the development of cultural heritage Spatial Data Infrastructures (SDIs) was proposed. It is designed to be an extension of the Protected Sites Data Specification, in order to enable a full integration of cultural heritage data. Due to the fast digital development there are many attempts to standardise cultural data (e. g. 3D digital models of sculptures, monuments, rooms, buildings and audiovisual data: music, film or stage performances). In Germany the idea of such a framework is developed by the NFDI4Culture consortium [154].

\section{Conclusions}

In this paper a multi-aspect analysis of $3 \mathrm{D}$ technologies in the aspect of both $\mathrm{ICH}$ and mixed $\mathrm{CH}$ for culture preservation is performed, based on three databases: Scopus, Web of Knowledge and IEEE Xplore. The performed analysis consisted of three main areas: general quantitative studies, detailed results and geographic, technological and product cross-section. In the paper, four questions were defined/stated in the Study questions section. Based on the obtained results it can be confirmed that the use of $3 \mathrm{D}$ digital technologies is increasing year by year. The results showed that the most important $\mathrm{ICH}$-focused topics presented in the research are: dance, $\mathrm{ICH}$ architecture and crafts. The interest in folklore dances and the need to consolidate them is clearly visible. They are used both for educational and scientific purposes. Currently, there is a growing interest in the method of producing everyday objects and the methods implemented in the construction of buildings in the past. The study carried out showed that the most popular 3D technologies used in $\mathrm{ICH}$ are: $3 \mathrm{D}$ modelling, motion capture, 3D visualization, VR and AR. The current rapid development of this technology allows scientists to permanently consolidate such a valuable and elusive culture that is passed on to the next generations, often fading away or being distorted. Most of the articles concern ICH in the areas of data documentation, data protection and reconstruction. They concern articles published in scientific journals and conference materials. There is a noticeable increase in publications from year to year. The preservation of cultural heritage has become an anchor of the past towards future generations due to $3 \mathrm{D}$ technologies.

The obtained results showed that $\mathrm{ICH}$ is an indispensable extension of $\mathrm{TCH}$. It is visible in the growing interest of $\mathrm{ICH}$ in the scientific studies. The society is aware of $\mathrm{ICH}$ loss, which is seen in the increasing number of research papers.

3D technologies are used in a wide range of applications. They concern not only the preservation of objects from the past, but also the development of today's culture. Due to the development of 3D technology and IT, it can be expected that they will be increasingly used in $\mathrm{ICH}$ issues. Their usage in various types of applications will allow the spread of knowledge about cultural heritage. This will enable for the preservation of many elements of culture, both tangible and intangible, that will be available to present and future generations.

\section{Abbreviations}

$\mathrm{CH}$ : Cultural heritage; TCH: Tangible cultural heritage; ICH: Intangible cultural heritage; 3D: three-dimensional; VR: Virtual reality; AR: Augmented reality.

\section{Acknowledgements}

Not applicable.

\section{Authors' contributions}

MSP: conceptualization, validation, formal analysis, investigation, resources, data curation, writing —original draft preparation, writing — review and editing, visaulization, supervision; MM: conceptualization, methodology, formal analysis, investigation, resources, data curation, writing —original draft preparation, writing - review and editing, supervision; PP: validation, investigation, resources, data curation, writing — original draft preparation, writing - review and editing, visaulization; EL: investigation, resources, data curation, writingoriginal draft preparation. All authors read and approved the final manuscript.

Funding

Not applicable.

Availability of data and materials

Not applicable.

\section{Declarations}

Ethics approval and consent to participate

Not applicable.

Consent for publication

Not applicable.

Competing interests

The authors declare that they have no competing interests.

Received: 16 July 2021 Accepted: 27 November 2021

Published online: 04 January 2022

\footnotetext{
References

1. Vecco M. A definition of cultural heritage: from the tangible to the intangible. J Cult Herit. 2010;11(3):321-4.
} 
2. What is Intangible Cultural Heritage? https://ich.unesco.org/en/what-isintangible-heritage-00003. Accessed 20 Apr 2021.

3. Lo P, Chan HHY, Tang AWM, Chiu DKW, Cho A, See-To EWK, Ho KKW, He $M$, Kenderdine S, Shaw J. Visualising and Revitalising traditional Chinese martial arts: Visitors engagement and learning experience at the 300 years of Hakka Kungfu. Library Hi Tech. 2019;37(2):273-92.

4. Wachowiak MJ, Karas BV. 3D scanning and replication for museum and cultural heritage applications. J Am Inst Conserv. 2009;48(2):141-58.

5. Priyadarshini R, Soumya A. Survey: classification and reconstruction of archaeological artefacts. Adv Intell Syst Comput. 2020;1112:439-45.

6. Montusiewicz J, Barszcz B, Dziedzic K. Photorealistic 3D digital reconstruction of a clay pitcher. Adv Sci Technol Res J. 2019;13(4):255-63.

7. Żyła K, Montusiewicz J, Skulimowski S, Kayumov R. VR technologies as an extension to the museum exhibition: A case study of the Silk Road museums in Samarkand. Muzeologia a Kulturne Dedicstvo. 2020;4:73-93.

8. Milosz M, Kesik J, Montusiewicz J. 3D scanning and visualization of large monuments of timurid architecture in central Asia - a methodical approach. ACM J Comput Cult He. 2020;14(1):1-31.

9. Milosz M, Skulimowski S, Kesik J, Montusiewicz J. Virtual and interactive museum of archaeological artefacts from Afrasiyab — an ancient city on the silk road. Digit Appl Archaeol Cult Heritage. 2020;18:1-12.

10. Morlando G, Lamera L, Guidi G. Temporary made permanent: Turning temporary exhibitions into fixed memories. In: 18th International Conference on Virtual Systems and Multimedia; 2012. pp. 19-24.

11. Intangible Heritage domains in the 2003 Convention. https://ich. unesco.org/en/intangible-heritage-domains-00052. Accessed 20 Apr 2021.

12. Logan WS. Closing pandoras box: human rights conundrums in cultural heritage. New York: Cultural heritage and human rights; 2007.

13. Conservation of cultural heritage. http://uis.unesco.org/en/glossaryterm/conservation-cultural-heritage. Accessed 23 Sept 2021.

14. Bercigli M. Dissemination strategies for cultural heritage: the case of the tomb of Zechariah in Jerusalem Israel. Heritage. 2019;2(20):1-8.

15. Kelly UA. Migration and education in multicultural world: culture, Loss and identity. USA: Palagrave Macmillan; 2009.

16. Bhugra D, Becker M. Migration, cultural bereavement and cultural identity. World Psychiatry. 2005;4(1):18-24

17. Migration and Its Impact on Cities. http://www3.weforum.org/docs/ Migration_Impact_Cities_report_2017_low.pdf. Accessed 23 Sept 2021).

18. Bentkowska-Kafel A, MacDonald L. Digital techniques for documenting and preserving cultural heritage. UK: ARC Humanites Press; 2009.

19. Repola L, Leidwanger J, Greene ES. Digital models for the analysis and enhancement of hybrid spaces: architecture of the mattanza. ISPRS Arch. 2020;13(3):443-50

20. Cristini V, García-Soriano L, Vegas F. Villages with fortified churches in transylvania: architecture, history and intangible culture. ISPRS Arch. 2020;13(3):249-54.

21. Wu J, Guo L, Jiang J, Sun Y. The digital protection and practice of intangible cultural heritage crafts in the context of new technology. E3S Web Conf. 2021;236:05024.

22. Rossau IG, Skovfoged MM, Czapla JJ, Sokolov MK, Rodil K. Dovetailing: safeguarding traditional craftsmanship using virtual, reality. Int J Intang Heritage. 2019;14:103-20.

23. Partarakis N, Zabulis X, Chatziantoniou A, Patsiouras N, Adami I. An approach to the creation and presentation of reference gesture datasets, for the preservation of traditional crafts. Appl Sci. 2020;10(20):1-17.

24. Jeong $E, Y u J$. Ego-centric recording framework for Korean traditional crafts motion. Lect Notes Comput Sci. 2018:11197:118-25.

25. Koutsabasis $\mathrm{P}$, Vosinakis $\mathrm{S}$. Kinesthetic interactions in museums: conveying cultural heritage by making use of ancient tools and (re-) constructing artworks. Virtual Real. 2018;22:103-18.

26. Carrozzino M, Scucces A, Leonardi R, Evangelista C, Bergamasco M. Virtually preserving the intangible heritage of artistic handicraft. J Cult Herit. 2011;12(1):82-7.

27. Wang $\mathrm{D}$, Zheng $\mathrm{CH}$. Research on the Digitalized Communication Planning of Chinese Intangible Cultural Heritage: Taking Ceramics as an Example. 5th International Conference on Education, Management, Information and Medicine (EMIM), Shenyang, China, Apr. 2015; 2015.
28. Lou L, Zhao F. Introduction of Canadian Project-based Teaching Approach to the Class of Intangible Cultural Heritage-Taking the Gold Lacquered Wood Carving Course in Animation Major for Example. 5th International Conference on Education and Education Management (EEM 2016), Sydney, Australia, Dec. 2016; 2016

29. Aoki R, Miyamoto R. Problems in Three-Dimensional Measurement of Japanese Kenjutsu Using Existing Sensing Devices. 2018 IEEE International Conference on Metrology for Archaeology and Cultural Heritage, MetroArchaeo 2018, Cassino, Italy, Oct. 2018; 2018.

30. Zhao G, Zan H, Di B, Zhu W, Yu Y. Research on virtual reconstruction technology of Tujia brocade handcrafts. 3D Res. 2018;9(4):54.

31. Farroni L, Mancini MF. Representation and Restoration Theories for a Digital Life of the Archival Architectural Drawings. In: Proceedings of the 2018 3rd Digital Heritage International Congress, Digital Heritage 2018-Held jointly with the 2018 24th International Conference on Virtual Systems and Multimedia, VSMM 2018; 2018.

32. Rallis I, Voulodimos A, Bakalos N, Protopapadakis E, Doulamis N, Doulamis A. Machine learning for intangible cultural heritage: a review of techniques on dance analysis. In: Liarokapis F, Voulodimos A, Doulamis $\mathrm{N}$, Doulamis A, editors. Visual computing for cultural heritage. Springer Series on Cultural Computing. Cham: Springer; 2020. p. 103-19.

33. Voulodimos A, Rallis I, Doulamis N. Physics-based keyframe selection for human motion summarization. Multimed Tools Appl. 2020;79(5-6):3243-59.

34. Voulodimos A, Doulamis N, Doulamis A, Rallis I. Kinematics-based Extraction of Salient 3D Human Motion Data for Summarization of Choreographic Sequences. In: proceedings—International Conference on Pattern Recognition vol. 2018-August, article no. 8545078; 2018. pp. 3013-3018.

35. Douka S, Ziagkas E, Zilidou V, Loukovitis A, Tsiatsos T. The 3D motion capturing process of greek traditional dance "Syrtos in Three" and a proposed method for the sex identification of performing dancers. Adv Intell Syst Comput. 2021. https://doi.org/10.1007/978-3-030-52575-0_ 31.

36. Ziagkas E, Zilidou V, Loukovitis A, Douka S, Tsiatsos T. Greek traditional dances capturing and a kinematic analysis approach of the Greek traditional dance "Syrtos" (Terpsichore Project). Adv Intell Syst Comput. 2021. https://doi.org/10.1007/978-3-030-49932-7 49.

37. Ziagkas E, Zilidou V, Loukovitis A, Douka S, Tsiatsos T. Greek Traditional Dances Capturing and a Kinematic Analysis Approach of the Greek Traditional Dance "Syrtos" (Terpsichore Project). 13th International Conference on Interactive Mobile Communication, Technologies and Learning, IMCL 2019, Thessaloniki, Greece, Oct.-Nov. 2019; 2019.

38. Rallis I, Georgoulas I, Doulamis N, Voulodimos A, Terzopoulos P. Extraction of key postures from 3D human motion data for choreography summarization. In: proceedings-9th International Conference on Virtual Worlds and Games for Serious Applications, VS-Games 2017: 2017. pp. 94-101.

39. Douka S, Ziagkas E, Zilidou V, Loukovitis A, Tsiatsos T. The 3D Motion Capturing Process of Greek Traditional Dance "Syrtos in Three" and a Proposed Method for the Sex Identification of Performing Dancers (Terpsichore Project). International Conference on Remote Engineering and Virtual Instrumentation, REV 2020, Athens, USA, Feb. 2020:2020.

40. Rallis I, Bakalos N, Doulamis N, Doulamis A, Voulodimos A. Bidirectional long short-term memory networks and sparse hierarchical modeling for scalable educational learning of dance choreographies. Vis Comput. 2021;37(1):47-62.

41. Rallis I, Bakalos N, Doulamis N, Voulodimos A, Doulamis A, Protopapadakis E. Learning Choreographic Primitives Through A Bayesian Optimized Bi-Directional LSTM Model. In: proceedings: International Conference on Image Processing, ICIP vol. 2019-September, art n. 8803118; 2019. pp. 1940-1944.

42. Rallis I, Protopapadakis E, Voulodimos A, Doulamis N, Doulamis A, Bardis G. Choreographic pattern analysis from heterogeneous motion capture systems using dynamic time warping. Technology. 2019;7(3):56.

43. Lim YK, Park JW. The way to preserve korean intangible cultural assets. In: HCl International 2018 - Posters Extended Abstracts; 2018. pp. 192-195.

44. Xiang L. Research on the construction of folk dance protection system based on OGRE. J Adv Oxid Technol. 2018;21(2):201803111. 
45. Ribeiro C, Dos Anjos RK, Fernandes C. Capturing and documenting creative processes in contemporary dance. In: ACM International Conference Proceeding Series article no. 3078041; 2017.

46. Tongpaeng Y, Rattanakhum M, Sureephong P, Wicha S. Implementing a tool for translating dance notation to display in 3D animation: A case study of traditional thai dance In: proceedings - 30th International Conference on Industrial, Engineering, and Other Applications of Applied Intelligent Systems, IEA/AIE 201; 2017. pp. 22-26.

47. Tongpaeng Y, Sureephong P, Rattanakhum M, Yu H. Thai dance knowledge archive framework based on Labanotation represented in 3D animation. 2nd Joint International Conference on Digital Arts, Media and Technology 2017: Digital Economy for Sustainable Growth, ICDAMT 2017, article no. 7904936; 2017. pp. 66-70.

48. Doulamis A, Voulodimos A, Doulamis N, Soile S, Lampropoulos A. Transforming intangible Folkloric performing arts into tangible choreographic digital objects: The Terpsichore approach. In: Proceedings of the 12th International Joint Conference on Computer Vision, Imaging and Computer Graphics Theory and Applications, vol. 5; 2017. pp. 451-460.

49. Tongpaeng Y, Maphon P, Sureephong P. Improving ThaiLabanXML standard for the automatic Thai laban drag drop system. ECTI DAMTNCON 2019-4th International Conference on Digital Arts, Media and Technology and 2nd ECTI Northern Section Conference on Electrical, Electronics, Computer and Telecommunications Engineering, article no. 8692313; 2019. pp. 168-173.

50. Tongpaeng Y, Nantapatsaran K, Sureephong P. Interpreting Thai laban notation into ThaiDanceXML. In: Proceedings of the 2018 International Conference on Digital Arts, Media and Technology (ICDAMT); 2018. pp. 173-178.

51. Fu JY, He XZ, Wan FC, Duan LL, Shan YM. Design and implementation of dance model based on 3D motion capture system. In: proceedings of the 2014 International Conference on Engineering Management and Industrial Engineering, EMIE 2014; 2015. pp. 47-52.

52. Hajdin M, Kico I, Dolezal M, Chmelik J, Doulamis A, Liarokapis F. Digitization and visualization of movements of slovak folk dances. Adv Intell Syst Comput. 2019;917:245-56.

53. Stavrakis E, Aristidou A, Savva M, Himona SL, Chrysanthou Y. Digitization of Cypriot Folk Dances. In: Ioannides M, Fritsch D, Leissner J, Davies R, Remondino F, Caffo R, editors. Progress in cultural heritage preservation. EuroMed 2012. Lecture Notes in Computer Science, vol. 7616. Berlin, Heidelberg: Springer; 2012. p. 404-13

54. Hisatomi K, Tomiyama K, Katayama M, Iwadate Y. Method of 3D reconstruction using graph cuts, and its application to preserving intangible cultural heritage. IEEE 12th International Conference on Computer Vision Workshops, ICCV Workshops; 2009. pp. 923-930.

55. Ji J, Cheng J, Fu R. Research on design process of small intangible cultural heritage art gallery based on VRP-MUSEUM technology-taking the art gallery of shanghai style lacquerware as an example. Commun Comput Inf Sci. 2019;1034:566-74.

56. Selmanovic, E.; Rizvic, S.; Harvey, C.; Chahin, M.; Ljivo, S. VR Video storytelling for intangible cultural heritagepreservation. In 2018 Eurographics Workshop on Graphics and Cultural Heritage, GCH 2018 2018, 57-66.

57. Rizvic S, Okanovic V, Boskovic D. Digital storytelling. Visual computing for cultural heritage. Springer Series on Cultural Computing. Cham: Springer; 2020, p. 347-67.

58. Shih N-J, Diao P-H, Qiu Y-T, Chen T-Y. Situated AR simulations of a lantern festival using a smartphone and lidar-based 3D models. Appl Sci. 2021;11(11):1-12.

59. Thomopoulos SCA, Tsimpiridis P. COSMOS. Cultural Osmosis - Mythology and Art: A Data Organization and Visualization Platform, with the Use of Al Algorithms. 8th European-Mediterranean Conference, EuroMed 2020, Lemesson, Cyprus, Nov. 2020; 2021.

60. Selmanović E, Rizvic S, Harvey C, Boskovic D, Hulusic V, Chahin M, Sljivo S. Improving accessibility to intangible cultural heritage preservation using virtual reality. J Comput Cult Heritage. 2020;13(2):13.

61. Yang T, Zhao R. Research on Combination of Intangible Cultural Heritage and Augmented Reality. In: McAnally E, Zhang Y, Green R, editors. Proceeding of the 2nd International Conference on Contemporary Education, Social Sciences ans Humanities. Book Series: Advances in Social Science Education and Humanities Research, Tretyakova. vol. 124; 2017. pp. 536-538.
62. Ćosović MC, Brkić BR. Game-based learning in museums-cultural heritage applications. Information (Switzerland). 2020;11(1):22.

63. Yilmaz E, Uturca D, Sahin C, Dagnino FM, Ott M, Pozzi F, Grammalidis N. Novel 3D game-like applications driven by body interactions for learning specific forms of intangible cultural heritage. In: proceedings-The VISAPP 2015-10th International Conference on Computer Vision Theory and Applications; 2015. pp. 651-660.

64. Dagnino FM, Pozzi F, Cozzani G, Bernava L. Using serious games for Intangible Cultural Heritage $(\mathrm{ICH})$ education: A journey into the Canto a Tenore singing style. In: Proceedings of the 12th International Joint Conference on Computer Vision, Imaging and Computer Graphics Theory and Applications (VISIGRAPP 2017); 2017. pp. 429-435.

65. Kennedy S, Fawcett R, Miller A, Dow L, Sweetman R, Field A, Campbell A, Oliver I, McCaffery J, Allison C. Exploring canons \& cathedrals with Open Virtual Worlds: The recreation of St Andrews Cathedral, St Andrews day, 1318. 2013 Digital Heritage International Congress (DigitalHeritage); 2013. pp. 273-280.

66. Bonenberger DJ, Harris TM. Placing Virtual Heritage: Reconciling virtual and cultural heritage with the Spatial Turn. In: Proceedings of the DigitalHeritage 2013-Federating the 19th IntI VSMM, 10th Eurographics GCH, and 2nd UNESCO Memory of the World Conferences, Plus Special Sessions fromCAA, Arqueologica 2.0 et al., vol. 2, article no. 6744827; 2013. pp. 601-604.

67. Haddad NA. Multimedia and cultural heritage: a discussion for the community involved in childrens edutainment and serious games in the 21st century. Virtual Archaeol Rev. 2016;7(14):61-73.

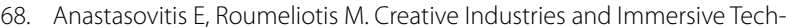
nologies for Training, Understanding and Communication in Cultural Heritage. 8th European-Mediterranean Conference, EuroMed 2020, Lemesson, Cyprus, Nov. 2020; 2021.

69. Partarakis N, Patsiouras N, Evdemon T, Doulgeraki P, Karuzaki E, Stefanidi E, Ntoa S, Meghini C, Kaplanidi D, Fasoula M, Zabulis X. Enhancing the Educational Value of Tangible and Intangible Dimensions of Traditional Crafts Through Role-Play Gaming. 9th EAl International Conference on Arts and Technology, Interactivity, and Game Creation, ArtsIT 2020, Aalborg, Virtual, Denmark, Dec. 2020; 2020.

70. Brusaporci S, Maiezza P, Tata A. Advanced heritage: From the virtual copy to a virtuous image of reality. 1st International and Interdisciplinary Conference on Image and Imagination, IMG 2019 Alghero, Italy, Jul. 2018; 2020

71. Gaugne R, Labaune F, Fontaine D, Cloirec GL, Gouranton V. From the engraved tablet to the digital tablet, history of a 15th-century music score. ACM J Comput Cult He. 2020;13(3):32-58.

72. Hu S, Du C, Song J, Tong C, Yuan Z. Research on Virtual Wind Instrument and Performance System Based on Dual Computer Communication. In: proceedings of 2020 IEEE International Conference on Power, Intelligent Computing and Systems, ICPICS 2020, article no. 9202031, 163-167.

73. Huang W, Xiang H, Li S. The application of augmented reality and unity 3D in interaction with intangible cultural heritage. Evol Intel. 2019. https://doi.org/10.1007/s12065-019-00314-6.

74. Yu X-XA, Peng Y-C, Huang X-Y. Research and development of prop system based on Unity 3D. J Univ Electron Sci Tech. 2014;41(4):523-8.

75. Dimitropoulos K, Manitsaris S, Tsalakanidou F, Nikolopoulos S, Denby B, Al Kork S, Grammalidis N. Capturing the intangible an introduction to the i-Treasures project. In: 2014 international conference on computer vision theory and applications (VISAPP); 2014. pp. 773-781.

76. Dagnino FM, Pozzi F, Yilmaz E, Dimitropoulos K, Tsalakanidou F. Designing Serious Games for ICH education. In: proceedings Digital Heritage International Congress, Digital Heritage 2015; 2015. pp. 615-618.

77. Cai D, Li Y, Huai Y. The intangible culture heritage "new ecology" under emotional demand of interactive experience. International Conference on Communications, Signal Processing, and Systems, CSPS 2018, Dalian, China, Jul. 2018; 2020.

78. Goenetxea J, Unzueta L, Linaza MT, Rodriguez M, OConnor N, Moran K. Capturing the sporting heroes of our past by extracting 3D movements from legacy video content. In: Euro-Mediterranean Conference; 2014. pp. 48-58.

79. Arévalo M, Cadi-Yazli N, Thalmann NM. Giving Life to John Calvin the Reformer. In: Euro-Mediterranean Conference, Springer, Cham; 2014. pp. 526-535. 
80. Linaza M, Moran K, OConnor N. Traditional Sports and Games: A New Opportunity for Personalized Access to Cultural Heritage. UMAP Workshops; 2013. pp. 1-6.

81. Tang F, Yu H, Natcher D, Zeng W, Phung T, Yu X, Li Y, Lu F, Rice A, Bodgan A, Disano J, Bell S. A web GIS platform for environmental livelihood value assessment in northeastern British Columbia. In: Proceedings CEUR Workshop, 2019 Conference on Spatial Knowledge and Information-Canada, vol. 2323, article no. 3, code 145561; 2019.

82. Jia ZY, Meng CY, Zhou ZX. A 3-D morphological approach on spatial form and cultural identity of ethnic mountain settlements: case from Guizhou, China. J Mount Sci. 2021;18(5):1144-58.

83. Yang WB, Yan YN. Planning by Using Digital Technology in the Reconstruction of Cultural Heritage Sites - a Case Study of Qiong-Lin Settlement in Kinmen Area. 26th International Symposium of ICOMOS/ ISPRS-International-Scientific-Committee-on-Heritage-Documentation (CIPA) on Digital Workflows for Heritage Conservation, Ottawa, Canada, Aug. 2017; 2017

84. Xu Q, Brown A, Moleta T, Schnabel MA, Rogers M. Inhabiting Prosperous Suzhou through Smart VR. 25th International Conference on Computer-Aided Architectural Design Research in Asia, CAADRIA 2020, Bangkok, Thailand, Aug. 2020; 2020.

85. Yinfang Z, Ding Q, Shen D. Character Design of Somatic Game from Perspective of Intangible Heritage Digital Protection. 4th International Conference on Data Mining, Communications and Information Technology, DMCIT 2020, Xian, China, May. 2020; 2020.

86. Yang T, Zhao R. Research on Combination of Intangible Cultural Heritage and Augmented Reality. 2nd International Conference on Contemporary Education, Social Sciences and Humanities (ICCESSH), Moscow, Russia, Jun. 2017; 2017.

87. Shi YW, Hao JF, Sun SQ. The Digital Protection of Intangible Cultural Heritage -The Construction of Digital Museum. 9th IEEE International Conference on Computer-Aided Industrial Design and Conceptual Design, Kunming, China, Nov. 2008; 2008.

88. Zhang Y, Han MQ, Chen WW. The strategy of digital scenic area planning from the perspective of intangible cultural heritage protection. Eurasip J Image Vide. 2018. https://doi.org/10.1186/s13640-018-0366-7.

89. Dai JB, Zhang LS. Design and Realization of Manchu Intangible Cultural Heritage Digital Exhibition Center Based on VR Technology. International Conference on Contemporary Education, Social Sciences and Humanities (ICCESSH), St Petersburg, Russia, Sep. 2016; 2016.

90. Parrinello S, DellAmico A. Experience of documentation for the accessibility of widespread cultural heritage. Heritage. 2019;2(1):1032-44.

91. Jung S, Choi T, Choi YS, Jang IS, Kim JW, Kim JS. Multisensory Capture System for the Preservation of Traditional Painting. 2019 International Conference on Advanced Communication Technology (ACACT), Pyeongchang, South Korea, Feb. 2019; 2019.

92. LiT, Chen Q. Transmission Path of Intangible Cultural Heritage Under Digital Technology. International Conference on Applications and Techniques in Cyber Intelligence, ATCI 2019, Shanghai, China, Jun. 2019; 2019

93. Lassandro P, Fioriello CS, Lepore M, Zonno M. Analysing, modelling and promoting tangible and intangible values of building heritage with historic flame lighting system. J Cult Herit. 2021;47(11):166-79.

94. Griffo M, Cimadomo P, Menconero S. Integrative IRT for documentation and interpretation of archaeological structures. IISPRS Arch. 2019;42(2/ W15):533-9.

95. Gao C, Yao J, Huang K, Qian K. Application and research of image-based modeling and 3D printing technology in intangible cultural heritage Quanzhou proceedingsmarionette protection. Int Comput Softw Appl Conf. 2019;1:914-5.

96. Manfren M, Nastasi B, Merli F, Vodola V. Acoustics and spatial sound distribution in the theatre comunale in Bologna, Italy. ProceedingsBuilding Simulation Applications, BSA 2019: 4th IBPSA-Italy Conference. Build. Simul. Appl. 2020. p. 239-44.

97. Álvarez-Morales L, Zamarreño T, Girón S, Galindo M. A methodology for the study of the acoustic environment of Catholic cathedrals: application to the Cathedral of Malaga. Build Environ. 2014;72:102-15.

98. Xu S. Intangible cultural heritage development based on augmented reality technology. In: proceedings - 2018 International Conference on Robots and Intelligent System, ICRIS 2018; 2018. pp. 352-355.
99. Wang H, Zhong J, Li W, Clarke C. Study on Restoration-Oriented Digital Visualization for Architectural Trim-Work of Guanlan Hall in Yuanming Yuan. International Conference on Human-Computer Interaction, Springer; 2020. pp. 573-594.

100. Banfi F, Brumana R, Stanga C. Extended reality and informative models for the architectural heritage: from scan-to-bim process to virtual and augmented reality. Virtual Archaeol Rev. 2019;10(21):14-30.

101. Themistocleous K, loannides M, Georgiou S, Athanasiou V. The First Attend for a Holistic HBIM Documentation of UNESCO WHL Monument: The Case Study of Asinou Church in Cyprus. Lect Notes Comput Sci. 2018;11197:408-14.

102. Xue C, Cao Y. Research on the application of $3 D$ digital technology in the Pizhou Running Zhuma. ACM Int Conf. 2020. https://doi.org/10. $1145 / 3425329.3425394$

103. Sánchez-Aparicio L, Moreno-Blanco R, Martín-Jiménez JA, RodríguezGonzálvez P, Muñoz-Nieto AL, González-Aguilera D. Smaertwall: a new web-based platform for valorization of the mediwal wall of Avila. ISPRS Arch. 2019:42(2/W15):1055-62.

104. Thomas EJ, Ross A. Counter-mapping theory and its application to a constantly changing Aboriginal stone arrangement site. Aust Archaeol. 2018;84(1):56-66.

105. Cao Y, Zhou Q. Art deco building data collection and protection of Nanjing based on 3D digital modeling technology -taking the site of China \& south sea bank Ltd for example. ACM Int Conf. 2020. https://doi.org/ 10.1145/3425329.3425396.

106. Mallik A, Chaudhury S, Chandru V, Srinivasan S. Digital Hampi: preserving Indian cultural heritage. Singapore: Springer Nature; 2018. p. 1-409.

107. Mallik A, Chaudhury S, Chandru V, Srinivasan S. Indian digital heritage: The next steps. Digital hampi: Preserving indian cultural heritage. Singapore: Springer Nature; 2018. p. 393-403.

108. Chroni A, Georgopoulos A. Documentation and 3D Digital Modelling: The Case of a Byzantine Christian Temple and an Ottoman Muslim Mosque in loannina City, Greece. 8th European-Mediterranean Conference, EuroMed 2020, Lemesson, Cyprus, Nov. 2020; 2021.

109. Tan G, Hao T, Liang S, Lin Z. Research on Construction Method of Multimedia Semantic Model for Intangible Cultural Heritage. In: Zhang T editors. Instrumentation, Measurement, Circuits and Systems. Advances in Intelligent and Soft Computing, 127; 2012. pp. 923-930.

110. Balletti C, Dabrowski M, Guerra F, Vernier P. Digital reconstruction of a lost heritage: The San Geminianos church in San Marcos Square in Venice. 2020 IMEKO TC-4 International Conference on Metrology for Archaeology and Cultural Heritage, MetroArchaeo. Trento, Virtual, Italy, Oct. 2020, Code 165450; 2020.

111. Kitsikidis A, Dimitropoulos K, Uğurca D, Bayçay C, Yilmaz E, Tsalakanidou F, Douka S, Grammalidis N. A game-like application for dance learning using a natural human computer interface. In: International Conference on Universal Access in Human-Computer Interaction, Springer, Cham; 2015. pp. 472-482.

112. Liu H. Digital expression and inheritance of the intangible cultural heritage "Regong Art". In: 2014 IEEE Workshop on Advanced Research and Technology in Industry Applications (WARTIA); 2014. pp. 172-174.

113. Rodríguez-Gonzálvez P, Fernández-Palacios BJ, Muñoz-Nieto AL, AriasSanchez P, Gonzalez-Aguilera D. Mobile LiDAR system: new possibilities for the documentation and dissemination of large cultural heritage sites. Remote Sens. 2017;9(3):189.

114. Chizfahm DM. The efficiency of visual buffer zone to preserve historical open spaces in Iran. Sustain Cities Soc. 2020;52:6.

115. Zakrajsek FJ, Vodeb V. Art Nouveau Danube Digital Repository. Lect Notes Comput Sci. 2018;11197:427-36.

116. de Fino M, Ceppi C, Fatiguso F. Virtual tours and informational models for improving territorial attractiveness and the smart management of architectural heritage: the 3D-imp-act project. ISPRS Arch. 2020;54(M-1):473-80.

117. Rambaldi G, Muchemi J, Crawhall N, Monaci L. Through the Eyes of Hunter-Gatherers: participatory 3D modelling among Ogiek indigenous peoples in Kenya. Inf Dev. 2007;23(2-3):113-8.

118. Cheng Y, Shouqian S, Caiqiang X. Recovery of cultural activity for digital safeguarding of intangible cultural heritage. In: Proceedings of the World Congress on Intelligent Control and Automation (WCICA), vol. 2, article no. 1714027; 2006. pp. 10337-10341. 
119. Yang C, Peng D, Sun S. Creating a virtual activity for the intangible culture heritage. In: Proceedings - 16th International Conference on Artificial Reality and Telexistence-Workshops, ICAT vol. 2, article no. 4089329; 2006. pp. 636-641.

120. Coren F, Visintini D, Prearo G, Sterzai P. Integrating LiDAR intensity measures and hyperspectral data for extracting of cultural heritage. In: Proceedings: CIRGEO (Hg.): Proceeding of Italy_Canada 2005 Workshop on 3D Digital Imaging and Modeling: Applications of Heritage, Industry, Medicine and Land. Padova; 2005.

121. Wang B, Dane GZ, De Vries B. Increasing awareness for urban cultural heritage based on 3D narrative system. ISPRS Arch. 2018:42(4/ W10):215-21.

122. Lo Turco M, Giovannini EC. Towards a phygital heritage approach for museum collection. J Archaeol Sci Rep. 2020;34:10263.

123. Li L, Choi W, Hachimura K, Yano K, Nishiura T, Tanaka HT. Virtual Yamahoko parade experience system with vibration simulation. ITE Trans Media Technol Appl. 2014;2(3):248-55.

124. Pietroni E. An augmented experiences in cultural heritage through mobile devices: "Matera tales of a city" project. 18th International Conference on Virtual Systems and Multimedia; 2012. pp. 117-124.

125. Arias-Espinoza P, Medina-Carrion A, Robles-Bykbaev $V$, RoblesBykbaev Y, Pesantez-Aviles F, Ortega J, Matute D, Roldan-Monsalve V. E-Pumapunku: An Interactive App to Teach Children the Cañari and Inca Indigenous Cultures during Guided Museum Visits. 2018 Congreso Internacional de Innovación y Tendencias en Ingeniería (CONIITI); 2018. pp. 1-5.

126. Medina-Carrión A, Arias-Espinoza P, Robles-Bykbaev V, Robles-Bykbaev Y, Pesántez-Avilés F, Ortega J. An interactive educational tool based on augmented reality, mobile applications and comic strips to teach children the Cañari and Inca cultures in the Ecuadorian context. 2018 Congreso Internacional de Innovación y Tendencias en Ingeniería (CONIITI); 2018. pp. 1-5.

127. Viinikkala L, Yli-Seppala L, Heimo OI, Helle S, Harkanen L, Jokela S, Jarvenpaa L, Korkalainen T, Latvala J, Paakyla J, Seppala K, Makila T, Lehtonen T. Reforming the representation of the reformation: Mixed reality narratives in communicating tangible and intangible heritage of the protestant reformation in Finland. In: Proceedings of the 2016 International Conference on Virtual Systems and Multimedia, VSMM, Category numberCFP16137-ART; Code 126637; 2016.

128. Wen Y, Chen J. Intangible cultural heritage display using augmented reality technology of Xtion PRO interaction. IJSSST. 2016;17(40):29.1-29.4.

129. Banfi F. Virtual Museums and Human-VR-Computer Interaction for Cultural Heritage Application: New Levels of Interactivity and Knowledge of Digital Models and Descriptive Geometry. 8th European-Mediterranean Conference, EuroMed 2020, Lemesson, Cyprus, Nov. 2020; 2021.

130. Ermrnyi T, Enegbuma WI, Icaacs N, Potangaroa R. Building information modelling workflow for heritage maintenance. 54th International Conference of the Architectural Science Association, ANZAScA 2020, Wellington, New Zealand, Nov. 2020; 2020.

131. Medici M, Ferrari F, Kuprashvili N, Meliva T, Bugadze N. CH digital documentation and 3D survey to foster the European integration process: The case study of Geguti Palace in Kutaisi, Georgia. In: the International European-Mediterranean Conference on Digital Heritage, EuroMed 2016; 2016. pp. 16-21.

132. Münster S, Prechtel N. Beyond software. Design implications for virtual libraries and platforms for cultural heritage from practical findings. In: Euro-Mediterranean Conference. Springer, Cham; 2014. pp. 131-145.

133. Wu G, Qiu M, Zhang Y, Zheng Y. Research and development of augmented reality childrens puzzle game based on vuforia. In: 2019 14th International Conference on Computer Science \& Education (ICCSE); 2019. pp. 354-359.

134. Adabala N, Datha N, Joy J, (...), Sankar A, Walton R. An interactive multimedia framework for digital heritage narratives. In: Proceedings of the 18th ACM international conference on Multimedia; 2010. pp. $1445-1448$.

135. Pettoello G. Exploring the inexistent. Scires IT. 2015;5(2):43-150.

136. Damiano R, Lieto A, Lombardo V. Ontology-based visualisation of cultural heritage. In: Proceedings-2014 8th International Conference on Complex, Intelligent and Software Intensive Systems, CISIS. article no. Article number 6915574; 2014. pp. 558-563.
137. Royan J, Gioia P, Cavagna R, Bouville C. Network-based visualization of $3 d$ landscapes and city models. IEEE Comput Grap Appl. 2007;27(6):70-9.

138. loannides M, Fritsch D, Leissner J, Davies R, Remondino F, Caffo R. Progress in Cultural Heritage Preservation: 4th International Conference EuroMed 2012, Lemessos, Cyprus, October 29-November 3, Proceedings (Vol. 7616). Springer Science \& Business Media; 2012.

139. Aditya T, Laksono D, Susanta FF, Istarno I, Diyono D, Ariyanto D. Visualization of 3D survey data for strata titles. ISPRS International Journal of Geo-Information. 2020;9(5): article no. 310.

140. Zlatanova S. Augmented reality technology. GISt Report, No. 17, Delft. 2002.

141. Bostanci E, Kanwal N, Clark AF. Augmented reality applications for cultural heritage using Kinect. Hum Centric Comput Inf. 2015;5(1):1-18.

142. Guttentag DA. Virtual reality: applications and implications for tourism. Tour Manag. 2010;31(5):637-51.

143. Rahul M. Review on motion capture technology. Global J Comput Sci Technol. 2018;18(1):23-6.

144. Pfister A, West AM, Bronner S, Noah JA. Comparative abilities of Microsoft Kinect and Vicon 3D motion capture for gait analysis. J Med Eng Technol. 2014;38(5):274-80.

145. Champion E, Rahaman H. 3D digital heritage models as sustainable scholarly resources. Sustainability (Switzerland). 2019;11(8):239-44.

146. Zhang Q. Discussion on the Expression of Digital Model for the Residential Buildings of Han Style. 2018 4th International Conference on Education, Management and Information Technology (ICEMIT 2018), Changchun, China. Jul. 2018; 2018.

147. Malliri A, Siountri K, Skondras E, Vergados DD, Anagnostopoulos CN. The Enhancement of Underwater Cultural Heritage Assets using Augmented Reality (AR). Conference on Underwater 3D Recording and Modelling-A Tool for Modern Applications and CH Recording, Limassol, Cyprus. May. 2019; 2019

148. Lo P, Chan H, Tang A, Chiu D. Visualising and revitalising traditional Chinese martial arts Visitors engagement and learning experience at the 300 years of Hakka Kungfu. Library Hi Tech. 2019;37(2):273-92.

149. Katayama M, Tomiyama K, Orihara Y, Iwadate Y. A 3D video system for archiving of japanese traditional performing art. In: Proceedings of the 12th International Display Workshops in Conjunction with Asia Display. 2005;(2):1743-1746.

150. Wu-Wei C. Body as Echoes: Cyber Archiving of Dazu Rock Carvings. 26th International Symposium of ICOMOS/ISPRS-International-ScientificCommittee-on-Heritage-Documentation (CIPA) on Digital Workflows for Heritage Conservation, Ottawa, Canada, Aug. 2017; 2017.

151. Xu W, Huo Y, Jin C, Shao X. Research on the Digital Promotion and Development of the Achang Forging Skills in Yunnan. ICMIR 2018: Recent Developments in Mechatronics and Intelligent Robotics, Kunming, China, Oct. 2018; 2018.

152. Peng $Y C, Y u X X$, Huang $X Y$. The Construction and Interaction of Virtual Scenes Based on Unity 3D. International Conference on Applied Mechanics and Mechatronics Engineering (AMME), Bangkok, Thailand, Oct. 2015; 2015

153. Fernández-Freire1 C, del-Bosque-González1 I, VicentGarcía JM, Pérez-Asensio1 E, Fraguas-Bravo A, UriarteGonzález A, FábregaÁlvarez P, Parcero-Oubiña C. A cultural heritage application schema: achieving interoperability of cultural heritage data in INSPIRE. IJSDIR. 2013;8:74-97.

154. ...Altenhoner R, Blumel I, Boehm F, Bove J, Bicher K, Bracht C, Brand O, Dieckmann L, Effinger M, Hagener M, Hammes A, Heller L, Kailus A, Kohle H, Ludwig J, Munzmay A, Pittroff S, Razum M, Rowenstrunk D, Sack H, Simon H, Schmidt D, Schrade T, Walzel A-V, Wiermann B. NFDI4Culture-Consortium for research data on material and immaterial cultural heritage. Res Ideas Outcomes. 2020;6:e57036.

\section{Publisher's Note}

Springer Nature remains neutral with regard to jurisdictional claims in published maps and institutional affiliations. 